\title{
Czochralski Growth and Properties of Scintillating Crystals
}

\author{
A. YOSHIKAWA ${ }^{a, b, *}$, V. $\mathrm{CHANI}^{a}$ AND M. NIKL ${ }^{c}$ \\ ${ }^{a}$ Institute for Materials Research, Tohoku University, 2-1-1 Katahira, Aoba-ku, Sendai 980-8577, Japan \\ ${ }^{b} \mathrm{NICHe}$, Tohoku University, 6-6-10 Aoba, Aramaki, Aoba-ku, Sendai 980-8579, Japan \\ ${ }^{c}$ Institute of Physics ASCR, Cukrovarnicka 10, 16253 Prague, Czech Republic
}

\begin{abstract}
The Czochralski method is one of the very few melt growth techniques that are industry friendly when considering the combination of quality, dimensions, and cost of the produced crystals suitable for their commercialization in scintillation detectors. This method is one of the oldest and most developed crystal growth processes regarding an adequate understanding the physical phenomena observed during solidification process and its practical expansion especially in the industrial scale production. It allows controllable formation of single-crystalline cylindrical ingots of various inorganic scintillation materials. The review summarizes recent progress on the Czochralski growth of a number of scintillation materials. The oxide crystals are mainly considered including the $\mathrm{Ce}$ and $\mathrm{Pr}-$ -doped $\mathrm{RE}_{3} \mathrm{Al}_{5} \mathrm{O}_{12}, \mathrm{RE}=\mathrm{Y}, \mathrm{Lu}$, aluminum garnets and newly discovered ultraefficient Ce-doped $\mathrm{Gd}_{3}(\mathrm{Ga}, \mathrm{Al})_{5} \mathrm{O}_{12}$ multicomponent garnet, high density $\mathrm{PbWO}_{4}$ and $\mathrm{CdWO}_{4}$ tungstates, Ce-doped $\mathrm{RE}_{2} \mathrm{SiO}_{5}, \mathrm{RE}=\mathrm{Y}, \mathrm{Gd}$, Lu, oxyorthosilicates and $(\mathrm{Y}, \mathrm{Lu}) \mathrm{AlO}_{3}$ aluminum perovskites and finally the classical $\mathrm{Bi}_{4} \mathrm{Ge}_{3} \mathrm{O}_{12}$ scintillator. Additionally, the details of the growth of other practically important non-oxide crystals, namely the Ce and Eu-doped LiCaAlF 6 neutron and ultraefficient Ce-doped $\mathrm{LaBr}_{3}$ scintillators, are discussed. The potential of novel micro-pulling down growth method is briefly described in the combinatorial search for new scintillator materials. Selected luminescence and scintillation characteristics including the spectra and decay kinetics, light yield and radiation resistance are also illustrated and overviewed.
\end{abstract}

DOI: 10.12693 /APhysPolA.124.250

PACS: $81.10 . \mathrm{Fq}, 78.70 . \mathrm{Ps}, 29.40 . \mathrm{Mc}, 78.55 . \mathrm{Hx}$

\section{Introduction}

Inorganic scintillating crystals are solid-state materials of high structural perfection that demonstrate scintillation (luminescence) after their excitation by some kind of ionizing radiation (vacuum ultraviolet (VUV), X-ray, or $\gamma$-ray), accelerated particles (electrons, alpha-particles, protons, or ions), or even neutrons. Absorbed energy of the incoming radiation and/or particles is transformed into the flash of light in near UV-visible spectral region. The ratio between the total emitted energy and energy of incoming high energy photon or particle defines the overall scintillation efficiency and can be at the best few tenths, but typically much less, see $[1,2]$. The luminescent characteristics of the scintillating crystals are defined by (1) intrinsic centers in the material, i.e. that of undoped crystals or (2) extrinsic centers that are due to impurities or defects formed in the crystal structure. Generally, the dopants are foreign ions that substitute for the cations or anions of the host [3].

Single-crystalline scintillators coupled with photodetectors are used in many high-tech fields that include high-energy particle physics, medical imaging (positron emission tomography, PET and related systems that help to visualize parts of the human body), border security, astrophysics, geophysical resource examination, etc. [4]. Depending on the application, various combinations of physical and scintillation characteristics of the crystals are considered. However, generally the scintil-

*corresponding author; e-mail: yoshikawa@imr.tohoku.ac.jp lating crystals have to possess high structural perfection, low content of non-desired impurities, reasonably uniform dopant distribution, and be produced with reasonable cost. Furthermore, high density (presence of heavy atoms in the structure) and maximum stopping power (high effective atomic number) are always desired to reduce dimensions of the detection elements and sensors. These requirements allow miniaturization of the devices and reduce the necessary size of the crystals to be grown.

Application of the crystal growth techniques that allow realistically fast growth of massive bulk crystals is always preferable in the industrial scale manufacturing process. The Czochralski (CZ) melt crystal growth is one of such techniques. However, this method cannot be used for any crystal. Congruent melting of the target material is one of the requirements that make application of this method possible and efficient. Table I illustrates list of selected scintillating crystals that are currently produced by the $\mathrm{CZ}$ method.

List of selected scintillating crystals.

TABLE I

\begin{tabular}{c|c|c|c|c}
\hline \hline Crystal & Density & $\begin{array}{c}\text { Melting } \\
\text { point }\end{array}$ & $\begin{array}{c}\text { Hygrosco- } \\
\text { picity }\end{array}$ & References \\
\hline $\mathrm{Pr}: \mathrm{Lu}_{3} \mathrm{Al}_{5} \mathrm{O}_{12}$ & 6.71 & 1980 & no & {$[5,6]$} \\
$\mathrm{Ce}: \mathrm{Gd}_{3}(\mathrm{Ga}, \mathrm{Al})_{5} \mathrm{O}_{12}$ & \multicolumn{2}{|c|}{ variable } & no & {$[7-9]$} \\
$\mathrm{PbWO}_{4}$ & 8.28 & 1160 & no & {$[10-13]$} \\
$\mathrm{CdWO}_{4}$ & 7.90 & 1325 & no & {$[14-15]$} \\
$\mathrm{Ce}: \mathrm{Lu}_{2} \mathrm{SiO}_{5}$ & 7.4 & 2150 & no & {$[16-19]$} \\
$\mathrm{Ce}: \mathrm{Y}_{2} \mathrm{SiO}_{5}$ & 4.45 & 2070 & no & {$[19]$} \\
$\mathrm{Ce}: \mathrm{Gd}_{2} \mathrm{SiO}_{5}$ & 6.71 & 1900 & no & {$[19]$} \\
$\mathrm{Bi}_{4} \mathrm{G}_{3} \mathrm{O}_{12}$ & 7.13 & 1050 & no & {$[20-22]$} \\
$\mathrm{Ce}: \mathrm{LuAlO}_{3}$ & 8.34 & $\approx 1900$ & no & {$[1,23,24]$} \\
$\mathrm{Ce}, \mathrm{Eu}: \mathrm{LiCaAlF}_{6}$ & 4.88 & 820 & no & {$[25-29]$} \\
$\mathrm{Ce}: \mathrm{LaBr}_{3}$ & 5.30 & 783 & yes, very high & {$[30-34]$}
\end{tabular}


The purpose of this review is to summarize recent success in CZ growth, details of the growth processes, and physical appearance and performance of number of important inorganic scintillating crystals of oxides and halides that have already been practically applied and used in the applications, particularly those listed above.

\section{Inorganic scintillating crystals}

Number of alkali metal halides, including most classical Tl:NaI and very recent $\mathrm{Ce}: \mathrm{LaBr}_{3}$ single crystals, together with other binary and complex halides demonstrate excellent scintillation performance. However, most of these materials are highly hygroscopic. Therefore, their practical application requires hermetic sealing to ensure their isolation from moisture in the surrounding. From this point of view the oxide crystals are more preferable considering the design of radiation detectors. Some of the prospective non-hygroscopic crystals are listed as follows: $\mathrm{CdWO}_{4}, \mathrm{PbWO}_{4}, \mathrm{Bi}_{4} \mathrm{Ge}_{3} \mathrm{O}_{12}, \mathrm{Ce}: \mathrm{Gd}_{2} \mathrm{SiO}_{5}$, $\mathrm{Ce}: \mathrm{Lu}_{2} \mathrm{SiO}_{5}, \mathrm{Ce}: \mathrm{Y}_{2} \mathrm{SiO}_{5}, \mathrm{Ce}: \mathrm{LuAlO}_{3}, \operatorname{Pr}(\mathrm{Ce}): \mathrm{Lu}_{3} \mathrm{Al}_{5} \mathrm{O}_{12}$, $\mathrm{Ce}: \mathrm{Gd}_{3}(\mathrm{Ga}, \mathrm{Al})_{5} \mathrm{O}_{12}, \mathrm{Eu}(\mathrm{Ce}): \mathrm{LiCaAlF}_{6}$, and $\mathrm{BaF}_{2}$.

\section{Czochralski crystal growth}

The Czochralski crystal growth process, developed formerly for the growth of crystals of metals, is about a century old [35], but it is still one of the leading crystal growth methods. It is well recognized in academic re-

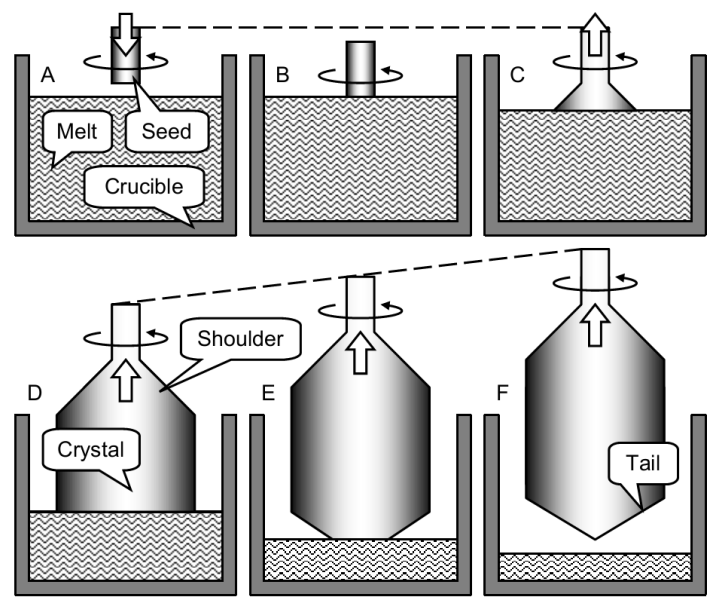

Fig. 1. Phases of typical Czochralski process including (A) approximation of the seed to the overheated melt, (B) immersion of the seed into the melt and their thermal equilibration, (C) pulling of the seed in upward direction with continuous increase of the crystal diameter and shoulder formation, (D) steady state of the pulling of the crystal of constant diameter, (E) ending the growth with continuous diameter decrease, and $(\mathrm{F})$ separation of the crystal from the melt and its following cooling to room temperature. search and industry. This technique allows controllable formation of single-crystal cylindrical ingots of various inorganic scintillating crystals. It can be also applied to the growth of organic crystals. The process is well established for the growth of semiconductors, oxides, fluorides, and other halide crystals as well as metals. In spite of its relative simplicity (Fig. 1), the process requires precise control of considerable number of factors that in different degree affect the crystal quality and commercial potential.

TABLE II

Czochralski growth parameters.

\begin{tabular}{l|l}
\hline \hline Item for control & Some factors to control \\
\hline crucible & $\begin{array}{l}\text { material composition, corrosion, melt- } \\
\text { ing point, shape and dimensions, con- } \\
\text { taminations, rotation, displacement, } \\
\text { etc. }\end{array}$ \\
\hline atmosphere & composition, pressure, flow rate, etc. \\
\hline melt & $\begin{array}{l}\text { composition, starting material treat- } \\
\text { ment, evaporation of constituents, } \\
\text { meniscus, corrosion, etc. }\end{array}$ \\
\hline seed & $\begin{array}{l}\text { structure, composition, orientation, di- } \\
\text { mensions, shape, etc. }\end{array}$ \\
\hline thermal aspect & $\begin{array}{l}\text { pulling rate, rotation (rate, accelera- } \\
\text { tion, direction) etc. }\end{array}$ \\
\hline $\begin{array}{l}\text { heating source and its power, hot zone } \\
\text { design and insulation materials, tem- } \\
\text { perature gradients, automatic diameter } \\
\text { control, etc. }\end{array}$ \\
\hline cost efficiency & $\begin{array}{l}\text { melt solidification fraction, cost of the } \\
\text { crucible and the melt ingredients, cost } \\
\text { of apparatus, time consumption for the } \\
\text { preparation of starting materials, total } \\
\text { time of the growth process, etc. }\end{array}$
\end{tabular}

List of such factors is demonstrated in Table II. Unfortunately, most of the reports on the Czochralski growth of scintillating crystals do not portray details of the process reflecting all of these factors. Thus, summary of the growth results presented below could not be considered as complete description of the technology. Nevertheless, many features of the crystal growth process are quite common and can be anticipated in the preparation of a new material, based on growth experience obtained before with other crystals.

\section{Oxide crystals}

In this section, growth of oxide scintillating crystals is summarized. In most cases, oxides have higher melting point than halides. Therefore, the growth apparatus must be designed to manage high power supply and to work at temperatures up to $2000^{\circ} \mathrm{C}$ or even more. In the following sections, the growth of selected types of oxide crystals is outlined.

\subsection{Garnets}

Growth of artificial garnet crystals is well established for decades [36], and it is commonly accepted that growth of yttrium-aluminum garnet $\mathrm{Y}_{3} \mathrm{Al}_{5} \mathrm{O}_{12}$ (YAG) from the melt can be successfully performed practically by any 
melt growth technique. From the point of view of crystal growth, YAG may be considered as typical crystalline substance that can play role of reference material. Its higher density analog, the $\mathrm{Lu}_{3} \mathrm{Al}_{5} \mathrm{O}_{12}$ ( $\mathrm{LuAG}$ ) has the same crystallographic structure and physicochemical properties that makes its growth also comparatively simple. On the other hand, LuAG is formed with much heavier rare-earth oxide $\mathrm{Lu}$ instead of $\mathrm{Y}$ that makes $\mathrm{LuAG}$ more attractive for scintillating applications [37].

As an example, the growth of Pr-doped LuAG was recently reported in [38-40]. The growth system was equipped with inductive radio-frequency ( $\mathrm{RF}$ ) heating. The 2 inches in diameter bulk single crystals were produced at pulling rate of $1 \mathrm{~mm} / \mathrm{h}$ and seed (Pr:LuAG) rotation of 8-12 rpm [5]. The growth apparatus used automatic diameter control system that was operated using signal received from the weight sensor. The Ir crucible was $\varnothing 100 \times 100 \mathrm{~mm}^{2}$ in dimensions, and it was protected from oxidation by Ar atmosphere.

The Pr:LuAG crystals of common shape (Fig. 2, left) contained many cracks at the shoulder and tail parts. This shortcoming was associated with high thermal stress acting in the upper portion of the crystal following from large cone angle and the stress in the tail part caused from concave shape of the solid/liquid interface. The problem was resolved by reducing the shoulder cone angle and flattening the solid-liquid interface, and as a result growth of crack-free crystals (Fig. 2, right) was established [5]. The length of the crystal was $110 \mathrm{~mm}$, and total solidification fraction for this process was about $40 \%$ with respect to the volume of the starting melt.

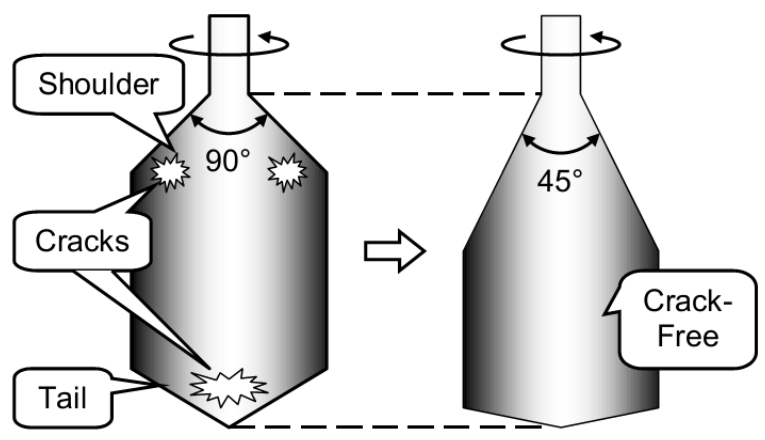

Fig. 2. Avoiding crack formation in 2-inch Pr: $\mathrm{Lu}_{3} \mathrm{Al}_{5} \mathrm{O}_{12}$ crystals grown by Czochralski method by modification of the crystal shape (shoulder angle) and modification of temperature gradients according to [5].

Another problem of the Pr-doped $\mathrm{Lu}_{3} \mathrm{Al}_{5} \mathrm{O}_{12}$ crystals is uniformity of the dopant distribution. From the chemical point of view, behavior of the host $\mathrm{Lu}^{3+}$ and guest $\mathrm{Pr}^{3+}$ cations in the garnet structure is comparable. However, dimensions of these cations are very different. Therefore, substitution of $\mathrm{Lu}^{3+}$ with $\mathrm{Pr}^{3+}$ is generally difficult. This was proven experimentally when composition of the grown Pr:LuAG and the dopant distribution along the growth axis were evaluated. The fraction of $\mathrm{Pr}^{3+}$ (with respect to $\mathrm{Lu}^{3+}$ ) in the starting melt composition was $2.5 \%$, however, that in the crystal was 0.18 0.25 or less with corresponding segregation coefficient of Pr to be about 0.07. Nevertheless, the crystals demonstrated acceptable uniformity regarding dopant content and the samples cut from different part of the crystal had practically the same light yield that was about three times greater than that of $\mathrm{Bi}_{4} \mathrm{Ge}_{3} \mathrm{O}_{12}$ (BGO) that is often considered as reference material regarding its scintillating performance. Optical properties and gamma-ray response of Pr:LuAG crystal including those containing different dopant content of $0.10,0.18$, and $0.22 \%$ are reported in [6].

$\mathrm{Ce}: \mathrm{Gd}_{3}(\mathrm{Ga}, \mathrm{Al})_{5} \mathrm{O}_{12}(\mathrm{Ce}: \mathrm{GAGG})$ garnet is the most recent multi-component garnet type crystal that demonstrates very high light yield with moderately fast scintillation response [41]. Growth of undoped and activated GAGG was well established by different melt growth techniques including Czochralski [8, 9], floating zone (FZ) [7], and micro-pulling-down ( $\mu$-PD) [42, 43]. In the past [8], undoped GAGG were grown considering their applications as material for the magnetic refrigerator. However, very recently the Ce-doped GAGG attracted much attention as a scintillating material.

In [8], the undoped GAGG crystals were produced in $\mathrm{N}_{2}+2 \% \mathrm{O}_{2}$ atmosphere from relatively small inductively heated Ir crucible of $\varnothing 50 \times 50 \mathrm{~mm}^{2}$ in dimensions. The growth was performed without automatic diameter control. The starting mixtures had excess of $\mathrm{Gd}_{2} \mathrm{O}_{3}$ of 0.02-0.15 per garnet formula unit with respect to ideal $\mathrm{Gd}_{3}(\mathrm{Ga}, \mathrm{Al})_{5} \mathrm{O}_{12}$ composition. This was necessary to perform the process from the Gd-enriched melt corresponding to congruently melting composition of GAGG. The steady state pulling rate for the step of constant diameter growth (Fig. 1D) was $2 \mathrm{~mm} / \mathrm{h}$ with crystal rotation rate of $35 \mathrm{rpm}$ that established flat solid-liquid interface. At faster rotation, the interface became convex resulting undesired crystal faceting. The crystal obtained from the $\mathrm{Gd}_{3.02}\left(\mathrm{Ga}_{0.7} \mathrm{Al}_{0.3}\right)_{4.98} \mathrm{O}_{12}$ melt was about $30 \mathrm{~mm}$ in diameter and $60 \mathrm{~mm}$ long, and it demonstrated reasonable optical quality and had no visible defects.

The quality of the $\mathrm{Gd}_{3}\left(\mathrm{Ga}_{1-x} \mathrm{Al}_{x}\right)_{5} \mathrm{O}_{12}$ crystals decreased considerably when concentration of $\mathrm{Al}$ was equal or exceeding 0.4 [8]. It was also noted that crack formation in the crystals was most probably associated with the strain induced in the crystal because of difference in ionic radii of $R\left(\mathrm{Al}^{3+}\right)=53.5 \mathrm{pm}$ and $R\left(\mathrm{Ga}^{3+}\right)=62.0 \mathrm{pm} \mathrm{[44]}$. Increased content of $\mathrm{Gd}^{3+}$ in the crystal reduced probability of crack formation as a result of its probable incorporation into octahedral sites of the garnet structure and its greater size of $R\left(\mathrm{Gd}^{3+}\right)=93.8 \mathrm{pm}$. In addition, it was detected that the crack formation was more intense when the crystals were faceted that was result of convex shape of the solid-liquid interface. The lattice parameters and the composition measurements demonstrated that the distribution coefficients of $\mathrm{Al}^{3+}$ was $K\left(\mathrm{Al}^{3+}\right)=1.14$ for $x=0.1$ and $K\left(\mathrm{Al}^{3+}\right)=1.07$ for $x=0.4$ considering $\mathrm{Gd}_{3}\left(\mathrm{Ga}_{1-x} \mathrm{Al}_{x}\right)_{5} \mathrm{O}_{12}$ garnet formula. Based on these val- 
ues, the existence of congruently melting composition of $\mathrm{Gd}_{3} \mathrm{Ga}_{3} \mathrm{Al}_{2} \mathrm{O}_{12}$ was predicted in [8].

$\mathrm{CZ}$ growth of the $\mathrm{Gd}_{3} \mathrm{Ga}_{3} \mathrm{Al}_{2} \mathrm{O}_{12}$ crystals modified with corresponding Ce-doping was also reported in [9]. Similar to [8], the crystals were grown using reduced pulling rate $(1 \mathrm{~mm} / \mathrm{min})$ and rotation of 4-12 rpm from Ir crucible of about the same dimensions also heated inductively. The growth atmosphere was $\mathrm{Ar}_{2}+1.5 \% \mathrm{O}_{2}$. This atmosphere was selected to prevent oxidation of the crucible $\left(\mathrm{Ar}_{2}\right)$ and to reduce evaporation of $\mathrm{Ga}_{2} \mathrm{O}_{3}$ from the surface of the melt $\left(\mathrm{O}_{2}\right)$ at the same time. $\mathrm{Lu}_{3} \mathrm{Al}_{5} \mathrm{O}_{12}$ crystal oriented along (100) axis was used as a seed. The crystals with diameter of $25 \mathrm{~mm}$ and length of $80-120 \mathrm{~mm}$ were produced with concentration of the Ce-dopant of $1.0,2.0$, and $3.0 \%$. The solidification fractions for these growths were $0.50,0.9$, and 0.48 , respectively, that exceeded prototype process reported in [8]. The interior parts of the crystals had perfect optical quality. However surface of the crystals was not transparent and irregular as a result of gallium oxide evaporation, thermal etching, and/or deposition of Ir particles originating from oxidation of the crucible material. According to composition analysis, the crystals were not perfectly uniform demonstrating moderate segregation for the host cations of $K\left(\mathrm{Al}^{3+}\right)=1.12$ and $K\left(\mathrm{Ga}^{3+}\right)=0.92$ and considerable segregation for the Ce-dopant of $K\left(\mathrm{Ce}^{3+}\right)=0.36$. This demonstrated that GAGG cannot be considered as true congruently melting compound at least at the compositional range reported.

Regarding dopant incorporation, it was noted in [9] that segregation coefficient $K\left(\mathrm{Ce}^{3+}\right)$ in GAGG was considerably greater than $K\left(\mathrm{Ce}^{3+}\right)=0.082$ reported for the YAG crystal grown by temperature gradient technique (TGT) in [45]. Also, according to [46], the Ce content in the YAG crystals produced by $\mathrm{CZ}$ method was 8.4 times less compared to the Ce-content in the melt, that also corresponds to $K\left(\mathrm{Ce}^{3+}\right)$ of about 0.1 . Thus, all observations demonstrated that GAGG crystals accept Ce-dopant much more easily than YAG that is very reasonable conclusion considering greater lattice parameter of GAGG compared to YAG and large size of $\mathrm{Ce}^{3+}$ cation.

Luminescence and scintillation characteristics and all the development of the LuAG-based scintillators including the discovery of ultra-efficient multi-component Ce:GAGG scintillators has been recently reviewed [37].

TABLE III

Optical, luminescence and scintillation characteristics of single crystals reported in this paper. Number in parenthesis in the scintillation decay time column represent the percentage of total intensity governed by the indicated decay time. Times in parenthesis in the LY column represent the time gates with which the LY was evaluated. See also web sites http://scintillator.lbl.gov/, http://crystalclear.web.cern.ch/crystalclear/for scintillation parameters.

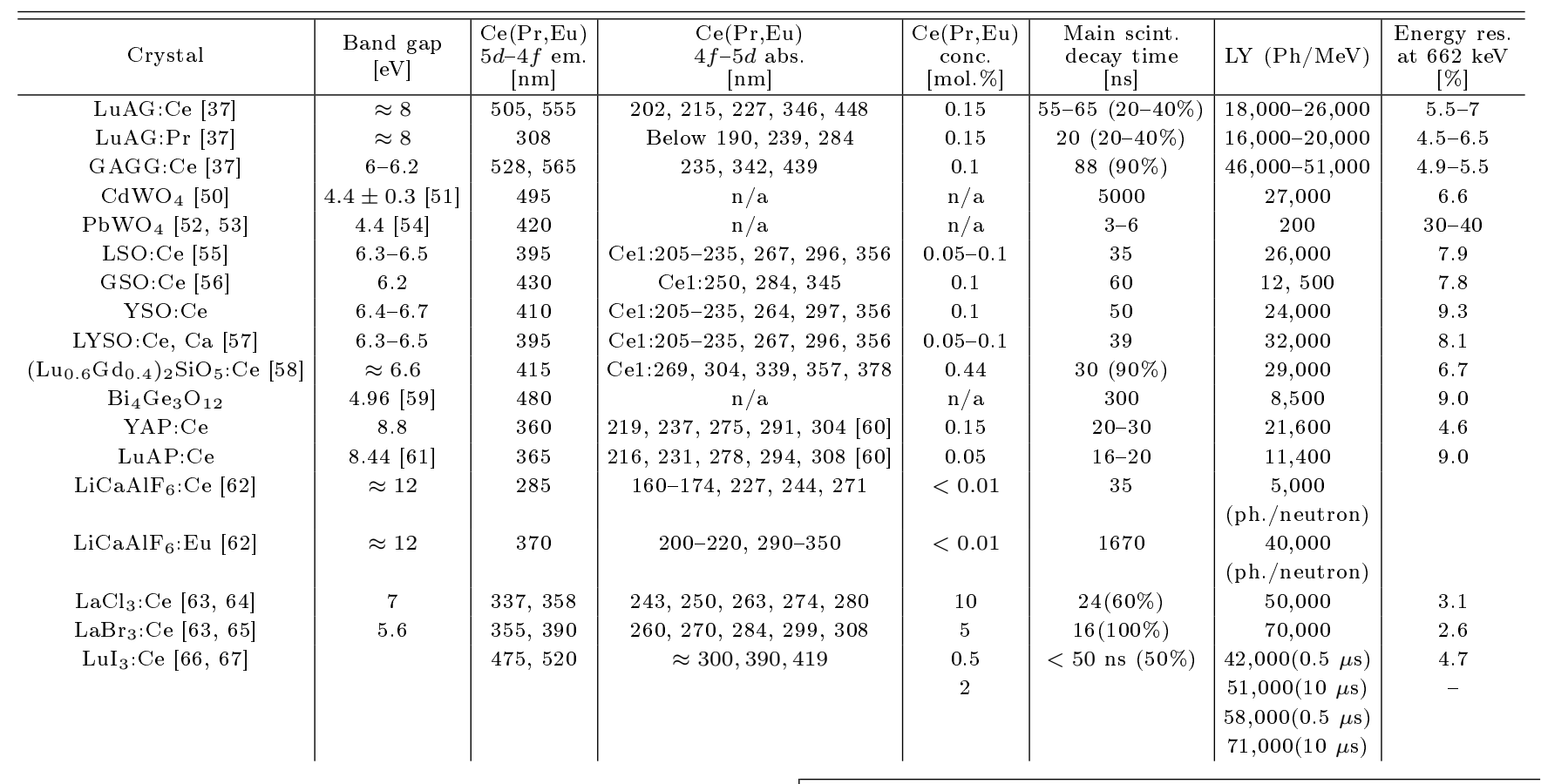

Optical, luminescence, and scintillation characteristics of Ce and Pr-doped LuAG and Ce-doped GAGG are summarized in Table III. $\mathrm{Ce}^{3+}$ center at the dodecahedral site of LuAG structure shows fast $5 d-4 f$ luminescence centered at about $510 \mathrm{~nm}$ (see Fig. 3) with the decay time of nearly 60 ns and the onset of thermal quenching above $700 \mathrm{~K}$ [47]. The same transition of $\mathrm{Pr}^{3+}$ is situated at $308 \mathrm{~nm}$ (see Fig. 3) with the room temperature decay 


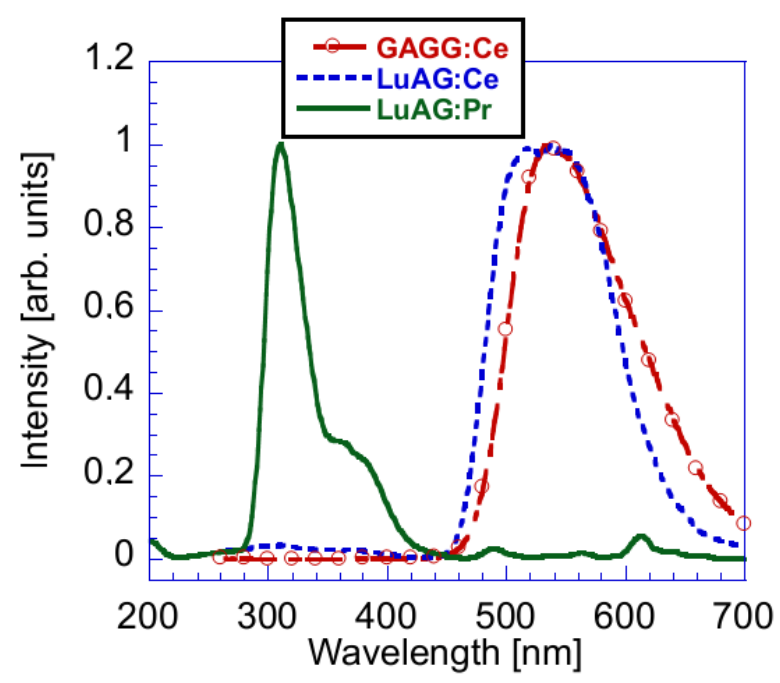

Fig. 3. Normalized radioluminescence spectra of Ce-doped LuAG and GAGG and Pr-doped LuAG (excitation X-ray, $40 \mathrm{kV}$ ).

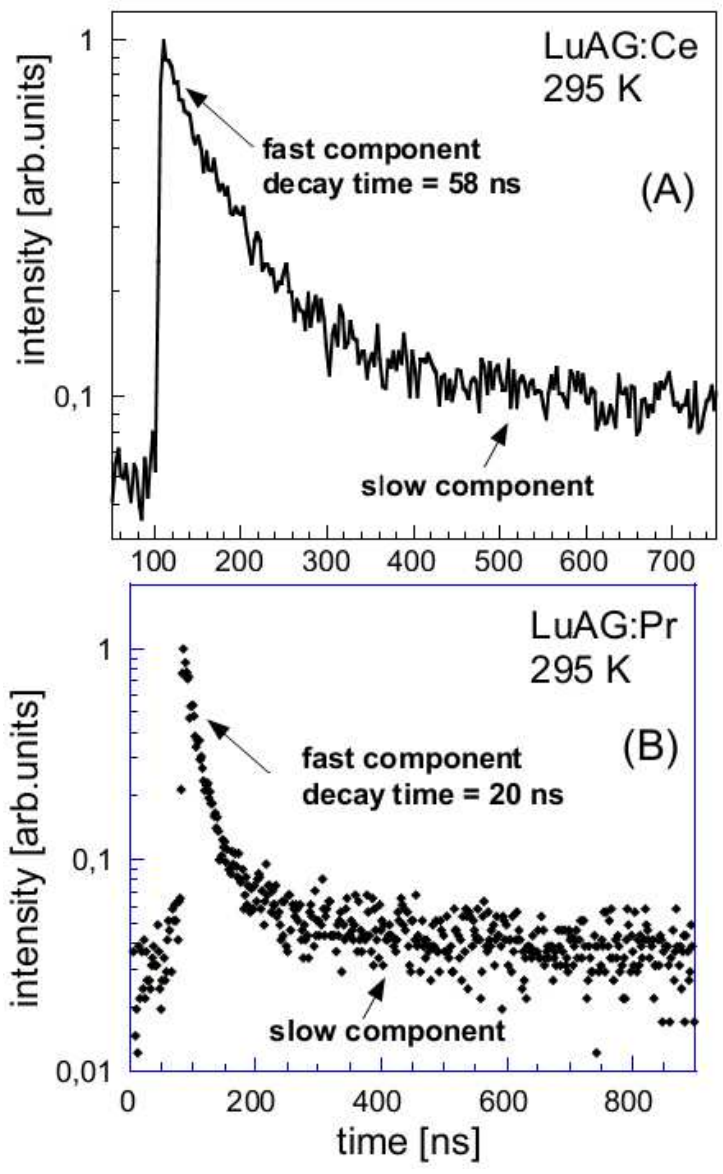

Fig. 4. Scintillation decays of Ce-doped (A) and Pr-doped (B) LuAG. Excitation source was ${ }^{22}$ Na radioisotope $(511 \mathrm{keV})$. time of $20 \mathrm{~ns}$ which makes it more suitable for fast scintillator. Moreover, energy resolution of Pr-doped LuAG was found excellent, below $5 \%$ at $662 \mathrm{keV}$ [48]. Scintillation response is in both cases troubled by slow components due to electron re-trapping at shallow traps in LuAG host [49] (Fig. 4) and elimination of these traps by the balanced admixture of $\mathrm{Gd}$ and Ga cations in multicomponent garnet host resulted in the enormous light yield increase [41].

\subsection{Tungstates: $\mathrm{PbWO}_{4}, \mathrm{CdWO}_{4}$}

Tungstate crystals including cadmium tungstate, $\mathrm{CdWO}_{4}$, lead tungstate, $\mathrm{PbWO}_{4}$, and others are high-density materials that show excellent stopping power for the $\mathrm{X}$ - and gamma-rays. They are chemically resistant and non-hygroscopic that makes them suitable for operation in number of device applications [68].

Because of the low melting point, the $\mathrm{PbWO}_{4}$ single crystals can be grown by the Czochralski method using platinum $(\mathrm{Pt})$ crucibles in air because the $\mathrm{Pt}$ is chemically resistant to normal atmospheric conditions (air). Particularly, the $\mathrm{PbWO}_{4}$ crystals reported in [10] were pulled from the melt with rate of $2 \mathrm{~mm} / \mathrm{h}$ and rotation of 20 $40 \mathrm{rpm}$ from $\mathrm{Pt}$ crucible of $35 \mathrm{~mm}$ in diameter. In these growths, the crystal diameter control was performed by monitoring the weight of the crucible with residual melt. The seed was oriented along $c$-axis direction. More detailed information about crystal growth details are available from [11]. The $\mathrm{PbWO}_{4}$ starting materials were produced by double heat treatment of initial mixtures at $850{ }^{\circ} \mathrm{C}$ for $20 \mathrm{~h}$ in air and at $900^{\circ} \mathrm{C}$ for $25 \mathrm{~h}$ after additional remixing. The resulting solid was inspected by $\mathrm{X}$-ray diffraction (XRD) to ensure complete reaction of the initial oxides of $\mathrm{PbO}$ and $\mathrm{WO}_{3}$ and absence of foreign phases of $\mathrm{PbO}, \mathrm{WO}_{3}$ or $\mathrm{Pb}_{2} \mathrm{WO}_{5}$. About $150 \mathrm{~g}$ of as produced starting solid was charged into the $\varnothing 50 \times 50 \mathrm{~mm}^{2}$ $\mathrm{Pt}$ crucible that was lately heated resistively in the hot zone unit with axial temperature gradient of $10-15^{\circ} \mathrm{C} / \mathrm{cm}$ above the melt level.

The authors of [11] paid special attention to the crack formation in $\mathrm{PbWO}_{4}$ crystals and the maneuvers that may decrease number of these defects. This problem was associated with significant difference in thermal expansion that occurred along (100) and (001) crystallographic directions. It was observed that quality of the crystals was improved by slow cooling the crystal to room temperature after its annealing. Also, the cracking was induced from asymmetry of the temperature distribution around the crystal and high axial temperature gradient above the melt. In addition, the seed misalignment caused non-uniform growth of the crystal in radial direction. Thereafter, the shape control of the conical shoulder part (Fig. 1C) was not possible and the growth was terminated.

In addition, the $\mathrm{PbWO}_{4}$ had tendency to crack when the diameter was increased very fast (Fig. $1 \mathrm{C}$, wide cone angle). This was associated with formation of convex solid/liquid interface and high temperature gradient occurring in the crystal because of the wide cone angle. 
This phenomenon was suppressed by adjusting the seed rotation to some appropriate value to avoid uncontrollable melt super-cooling. Finally, the best seed rotation rate observed in [11] was $25-30 \mathrm{rpm}$. The crack-free crystal reported had cone angle of about 90 similar to that illustrated in Fig. 1F, and it was grown with almost flat solid/liquid interface. The diameter of the crystal on its cylindrical part (Fig. 1D) was controlled by modification of the temperature of the melt. The pulling-up rate did not exceed $3 \mathrm{~mm} / \mathrm{h}$ because its increase to $4-5 \mathrm{~mm} / \mathrm{h}$ resulted in reduction of the crystal transmission partially due to unavoidable incorporation of the foreign phase inclusions. To reduce the crystal stresses and the crack formation, the as grown crystals were annealed at $1000^{\circ} \mathrm{C}$ for $5 \mathrm{~h}$ and then cooled down to room temperature at the rate of about $10^{\circ} \mathrm{C} / \mathrm{h}$.

The optical transmission spectra of the $3 \mathrm{~mm}$ thick specimens cut perpendicular to the growth axis from the top and middle parts of the $\mathrm{PbWO}_{4}$ crystals grown in [11] did not demonstrate any absorption around $430 \mathrm{~nm}$ (yellow coloration). However, those cut from the bottom part of the crystal had some absorption in this spectral region. This absorption was reduced when the crystals were grown from the melts obtained by re-melting of the crystals grown in previous experiments. For such crystals, the uniformity of the transmittance along the growth axis was considerably better.

Mass production of $\mathrm{PbWO}_{4}$ crystals was well established quite some years ago. Fabrication and delivery of more than one thousand of certified scintillation elements per month was reported back in 2005 [12]. It was also noted in [13] that most of parameters of the crystals were well reproducible, and significantly less than $10 \%$ of the crystals were rejected as not satisfying the standards of quality control for their usage in calorimetric detectors in new high-energy physics accelerators.

Cadmium tungstate, $\mathrm{CdWO}_{4}$ is another scintillating crystal of great importance particularly to be used in computed tomography and radiation monitoring systems [14]. It crystallizes in the wolframite structure with $\mathrm{Cd}$ and $\mathrm{W}$ cations sited in octahedral positions of the crystalline lattice. In [14], the $\mathrm{CdWO}_{4}$ were produced by the $\mathrm{CZ}$ method on the seeds oriented along (010) cleavage plane. The crystals were grown from $\mathrm{Pt}$ crucibles heated inductively and surrounded with alumina ceramic for thermal insulation. The diameter of the crystals was monitored with weight sensors, and the growths were performed in oxidizing or inert atmosphere. The crystals produced were $\varnothing 50 \times 150 \mathrm{~mm}^{2}$ in dimensions. The crystals were generally colorless and free of visible inclusions when solidification fraction did not exceed one-third part of the starting melt and when the diameter of the crystals was not greater than $50 \%$ of crucible diameter. However, larger crystals exceeding $60 \mathrm{~mm}$ in diameter contained macrodefects in the core part and at the bottom fraction of the crystals. The $\mathrm{CdWO}_{4}$ crystals reported contained pores with dimensions varied from 20 to $150 \mu \mathrm{m}$. According to [14], the growth was performed at $1350^{\circ} \mathrm{C}$, and at this temperature range the melt lost part of $\mathrm{CdO}$ as a result of its decomposition and evaporation. Therefore, the $\mathrm{CdO}$ solid particles were always found on the walls of the furnace and the remained melt was always enriched with $\mathrm{WO}_{3}$ as compared with stoichiometric composition of $\mathrm{CdWO}_{4}$. This melt composition instability was responsible for formation of secondary phase greenish inclusions of solid $\mathrm{WO}_{3}$ particles incorporated into bottom (tail) part of the crystals. Formation of cracks parallel to the (010) cleavage plane is another type of imperfections found in the $\mathrm{CdWO}_{4}$ crystals produced by conventional CZ method [15].

Growth of the $\mathrm{CdWO}_{4}$ crystals by low thermal gradient $\left(0.1-1^{\circ} \mathrm{C} / \mathrm{cm}\right) \mathrm{CZ}$ method was reported in [15]. In this method, the growth was performed from Pt crucible of $\varnothing 70 \times 200 \mathrm{~mm}^{2}$ in dimensions placed inside three-zone furnace heated resistively and providing temperature gradient of about $1^{\circ} \mathrm{C} / \mathrm{cm}$. The progress of the process was controlled by weight sensor, and the growth atmosphere was air. Two practices were applied to suppress undesired evaporation of $\mathrm{CdO}$ leading to progressed non-stoichiometry of the melt. Firstly, the crystal diameter was set to be relatively close to the crucible diameter leaving about $30-40 \%$ of the free surface of the melt at direct contact with air above the melt. Secondly, the top of the crucible was covered with conical lid equipped with small opening in the center providing pass for the seed holder rod. In such conditions (Fig. 5), the total amount of evaporated material was less than $0.2-0.5 \mathrm{wt} \%$ because the melt was not overheated regarding the melting point (the melt temperature was almost constant and equal to the melting temperature). As a result, $90 \%$ of the starting melt could be transformed into high-quality single-crystalline product with dimensions of $\varnothing 45 \times 150 \mathrm{~mm}^{2}$. It was demonstrated in [15] that growth results were not affected very much by changing the rotation rate within the range of $5-20 \mathrm{rpm}$ or practicing the reverse rotation.

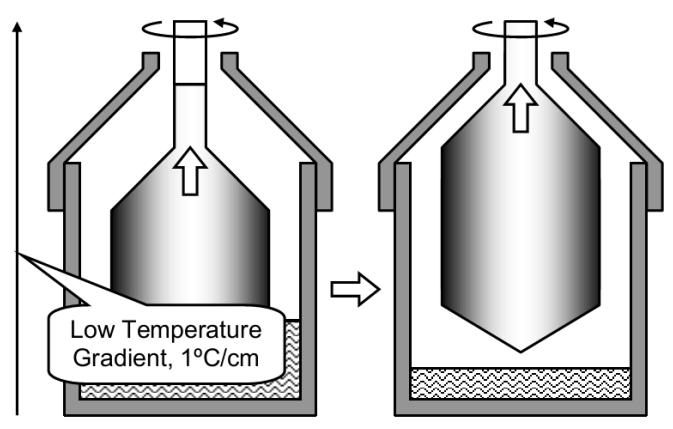

Fig. 5. Growth of the $\mathrm{CdWO}_{4}$ [15] and $\mathrm{Bi}_{4} \mathrm{Ge}_{3} \mathrm{O}_{12}$ [22] crystals by low thermal gradient $\left(0.1-1^{\circ} \mathrm{C} / \mathrm{cm}\right) \mathrm{CZ}$ method.

Intense study of the $\mathrm{PbWO}_{4}$ single crystals in 1990's was initiated due to selection of this material for the new generation of calorimetric detectors in Large Hadron Collider in CERN, see reviews [52, 53]. Later on, various electron trapping and hole trapping centers were system- 
atically characterized $[69,70]$ and their role in scintillation mechanism clarified. Luminescence of $\mathrm{PbWO}_{4}$, $\mathrm{CdWO}_{4}$ and other scheelite or wolframite structure tungstates are of self-trapped or trapped exciton nature and determined by the transition in the oxyanion group which results in violet-blue $(420 \mathrm{~nm})$ and blue-green (480 nm) emission bands in $\mathrm{PbWO}_{4}$ and $\mathrm{CdWO}_{4}$ single crystals, respectively. Essential difference between the decay time and quantum efficiency of excitonic luminescence around room temperature in $\mathrm{PbWO}_{4}$ (few nanosecond decay time and few percent efficiency) and $\mathrm{CdWO}_{4}$ (ten microsecond decay time and $100 \%$ efficiency) are due to different temperature stability of the exciton states. In $\mathrm{PbWO}_{4}$, rather low binding energy of exciton of about $0.075 \mathrm{eV}$ [71] results in its thermal disintegration already around $150-180 \mathrm{~K}$, while an onset of thermally induced ionization and/or quenching of luminescence in $\mathrm{CdWO}_{4}$ occurs well above room temperature [72].

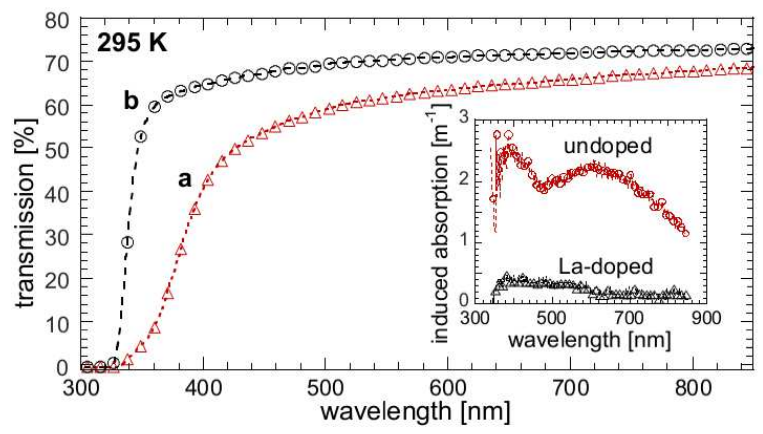

Fig. 6. Initial transmission and irradiation $\left({ }^{60} \mathrm{Co}\right.$ radioisotope, 10 Gy dose) induced absorption in the inset of the couple of equivalently grown undoped (a) and La-doped (100 at. ppm in the crystal) (b) $\mathrm{PbWO}_{4}$ single crystals. Reprinted from [52].

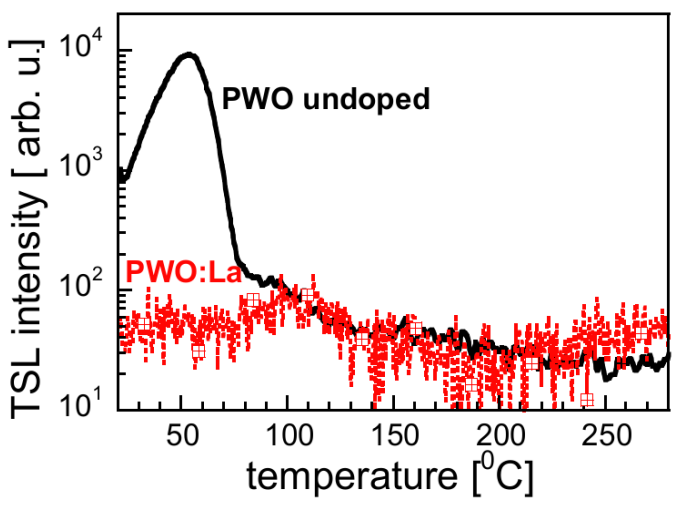

Fig. 7. Spectrally unresolved thermo-luminescence glow curve above room temperature after X-ray irradiation at room temperature, reprinted from [52].

Optimization of the $\mathrm{PbWO}_{4}$ and $\mathrm{CdWO}_{4}$ scintillation characteristics was focused mainly on their radiation hardness [52, 53] and afterglow [73], respectively, and has been achieved by the aliovalent doping. While in the for- mer case the stable trivalent impurities (La, Gd, Y, Lu) increased the radiation hardness even several times compared to the high-purity and high-quality undoped crystal, in the latter case the monovalent dopants $(\mathrm{Li}, \mathrm{Na})$ have been most successful choice. The magnitude of this effect in the $\mathrm{PbWO}_{4}$ is demonstrated in Figs. 6 and 7 where the $\gamma$-ray irradiation induced absorption and thermoluminescence glow curve are displayed. Trivalent doping at $\mathrm{Pb}^{2+}$ site dramatically decreased the energy storage and color centers creation in the lattice due to the excess charge provided. Optical, luminescence and scintillation characteristics of $\mathrm{CdWO}_{4}$ and $\mathrm{PbWO}_{4}$ are summarized in Table III.

\subsection{Oxyorthosilicates: $\mathrm{RE}_{2} \mathrm{SiO}_{5}(\mathrm{RE}=$ rare earths)}

Cerium-doped oxyorthosilicates of rare-earth metals is another class of important scintillating oxide crystals. $\mathrm{Ce}: \mathrm{Lu}_{2} \mathrm{SiO}_{5}, \mathrm{Ce}: \mathrm{Y}_{2} \mathrm{SiO}_{5}$, and $\mathrm{Ce}: \mathrm{Gd}_{2} \mathrm{SiO}_{5}$ are widely used for gamma-ray detection and other applications $[18,19]$. These materials are represented by general formula of $\mathrm{Ce}: \mathrm{RE}_{2} \mathrm{SiO}_{5}$, where $\mathrm{RE}$ is lanthanide metal. Growth of such crystals by the Czochralski method is well established for decades due to their congruent melting [16-19]. Regarding the structure, the crystals formed by large rare-earth cations from $\mathrm{Tb}^{3+}$ to $\mathrm{La}^{3+}$ solidify in monoclinic structure with space group $P 2_{1} / c$. However, those based on small cations from $\mathrm{Lu}^{3+}$ to $\mathrm{Dy}^{3+}$ form monoclinic structure with space group $C 2 / c$ [16]. In the first case of $\mathrm{Gd}_{2} \mathrm{SiO}_{5}$ type structure $\left(P 2_{1} / c\right)$, the rare-earth sites have coordination numbers $\mathrm{CN}=7$ and $\mathrm{CN}=9$. However, in the case of $\mathrm{Lu}_{2} \mathrm{SiO}_{5}$ type crystals, the corresponding numbers are $\mathrm{CN}=6$ and $\mathrm{CN}=7$. As a result, higher coordination numbers allow easier incorporation of the large $\mathrm{Ce}^{3+}$ dopant. Therefore, the segregation coefficients of $\mathrm{Ce}^{3+}$ are about 0.6 [16] or 0.56 [19] for $\mathrm{Gd}_{2} \mathrm{SiO}_{5}, 0.34$ [19] for $\mathrm{Y}_{2} \mathrm{SiO}_{5}$, and 0.2 [16] or 0.22 [19] for $\mathrm{Lu}_{2} \mathrm{SiO}_{5}$.

Growth of $\mathrm{Lu}_{2} \mathrm{SiO}_{5}$ from standard iridium crucibles is comparatively difficult because the melting point of $\mathrm{Lu}_{2} \mathrm{SiO}_{5}\left(2150^{\circ} \mathrm{C}\right)$ is relatively close to the melting point of Ir. However, the melting temperature may be noticeably reduced $\left(2100^{\circ} \mathrm{C}\right)$ by partial and isomorphic substitution of $\mathrm{Lu}$ with $\mathrm{Gd}$ as it was reported in [16]. Alternatively, $\mathrm{Gd}_{2} \mathrm{SiO}_{5}$ melts at lower temperature of about $190{ }^{\circ} \mathrm{C}$ that is well acceptable for Ir crucibles because it is even less than that of YAG crystals produced commercially for decades. On the other hand, $\mathrm{Gd}_{2} \mathrm{SiO}_{5}$ cleaves, and it has not as good scintillating performance as that of $\mathrm{Lu}_{2} \mathrm{SiO}_{5}$ [16].

The CZ growth of $\mathrm{Lu}_{2} \mathrm{SiO}_{5}$ crystals of $40-80 \mathrm{~mm}$ in diameter was reported in [17]. The crucibles were made of Ir and were of $60-120 \mathrm{~mm}$ diameter. The growths were performed in gas flow, closed atmosphere, or in vacuum. The crystals were doped with $\mathrm{Ce}, \mathrm{Ce}+\mathrm{Tb}, \mathrm{Ce}+\mathrm{Mg}$, and $\mathrm{Ce}+\mathrm{Ca}$, and the melting points for corresponding starting materials were referred in [17] to be in the range of $1970-1980^{\circ} \mathrm{C}$. Depending on the growth process, the pulling rate was $0.7-2.0 \mathrm{~mm} / \mathrm{h}$, and the rotation rate was 
8-15 rpm. The crystal diameter was $30-78 \mathrm{~mm}$, and the crystal length was in the range of $70-170 \mathrm{~mm}$.

$\mathrm{Lu}_{2} \mathrm{SiO}_{5}$ is usually doped with $0.05-0.5 \%$ of $\mathrm{Ce}$ [18]. However, in some cases $[17,18]$ co-doping supports better scintillating performance. For example, incorporation of $\mathrm{Ca}^{2+}$ into $\mathrm{Ce}: \mathrm{Lu}_{2} \mathrm{SiO}_{5}$ may improve the light yield and the decay time, and effect of the co-dopant depends on its content in the crystal. On the other hand, this co-doping may reduce growth stability (acentric growth) even when the process conditions including temperature gradients in the hot zone remain unchanged. This phenomenon was particularly associated in [18] with reduction of the surface tension of the melt when it was enriched with $\mathrm{Ca}^{2+}$. This shortcoming was suppressed by incorporation of additional compensating co-dopant of Zn into the structure. As a result, the acceptable surface tension was restored, stabilizing the growth process without reduction of scintillation performance of the crystal. The experiments demonstrated that amount of the $\mathrm{Zn}$ in the melt should be greater than that of $\mathrm{Ce}$ and $\mathrm{Ca}$.

In [18], the $\varnothing 32 \times 100 \mathrm{~mm}^{2}$ crystals were grown by $\mathrm{CZ}$ method from the melts of $\mathrm{Ce}_{0.02} \mathrm{Lu}_{1.98} \mathrm{SiO}_{5}$ composition undoped and co-doped with $\mathrm{Ca}$ and $\mathrm{Ca}-\mathrm{Zn}$. The co-dopant contents in the melt varied in the range of $0.1-$ 0.4 at.\% (relative to content of lutetium in the melt) for $\mathrm{Ca}$ and $0.1-0.6$ at.\% for Zn. It is evident that actual Ce and co-dopant contents in the crystals were different compared to the melt composition as a result of segregation. The growths were performed on (100)-oriented seed from the $\varnothing 60 \times 60 \mathrm{~mm}^{2}$ cylindrical Ir crucibles heated inductively, and the surrounding atmosphere was $\mathrm{N}_{2}+0.7 \% \mathrm{O}_{2}$. The pulling rate was $1.5 \mathrm{~mm} / \mathrm{h}$, and the rotation rate was $10 \mathrm{rpm}$. The $25 \%$ increase of the light output was detected for the crystal with $0.1 \% \mathrm{Ca}$-co-doping concentration as compared to the Ce-only doped reference specimens. Following increase of the Ca-content in the Ce-doped $\mathrm{Lu}_{2} \mathrm{SiO}_{5}$ was accompanied by continued decrease of the light yield. Regarding the decay time, the fastest decay (28-31 ns) was observed in the crystals containing maximal Ca content of 0.4 at.\%. As for the $\mathrm{Zn}^{2+}$ co-doping made for stabilization of the growth, it did not affect the light yield and the decay process considerably. Also, both co-dopants of $\mathrm{Ca}$ and $\mathrm{Zn}$ did not influence the peak emission wavelength of $416 \mathrm{~nm}$ [18].

Growth of the Ce: $\mathrm{Y}_{2} \mathrm{SiO}_{5}$ crystals from the melts of $\mathrm{Ce}_{0.02} \mathrm{Y}_{1.98} \mathrm{SiO}_{5}$ and $\mathrm{Ce}_{0.02} \mathrm{Ca}_{0.02} \mathrm{Y}_{1.96} \mathrm{SiO}_{5}$ nominal compositions in the conditions similar to those described in the above paragraphs was reported in [19]. The crystals had no cracks and demonstrated reasonably good shape that was almost as good as that of the Ce: $\mathrm{Lu}_{2} \mathrm{SiO}_{5}$ produced at comparable conditions. However, in the case of co-doping of $\mathrm{Ce}: \mathrm{Y}_{2} \mathrm{SiO}_{5}$ with $\mathrm{Ca}$, the increase of the scintillation light yield was negligible (around 5\% only) that was much less relatively to $\mathrm{Ce}: \mathrm{Lu}_{2} \mathrm{SiO}_{5}$ (over 20\%).

The crystals of Ce: $\mathrm{Gd}_{2} \mathrm{SiO}_{5}$ grown from the melts of $\mathrm{Ce}_{0.02} \mathrm{Gd}_{1.98} \mathrm{SiO}_{5}$ and $\mathrm{Ce}_{0.02} \mathrm{Ca}_{0.02} \mathrm{Gd}_{1.96} \mathrm{SiO}_{5}$ [19] compositions had cracks. This was associated with using of iridium rod as a seed and with easy cleaving of $\mathrm{Gd}_{2} \mathrm{SiO}_{5}$ as compared with $\mathrm{Lu}_{2} \mathrm{SiO}_{5}$ and $\mathrm{Y}_{2} \mathrm{SiO}_{5}$. Similar observations were reported in [16] for the crystal grown on iridium rods as a seed from the melts of $\mathrm{Gd}_{2} \mathrm{SiO}_{5}$ and $\mathrm{Gd}_{1.8} \mathrm{Lu}_{0.2} \mathrm{SiO}_{5}$ compositions with the cracks progressed along (100) and (010) planes. Formation of these cracks was successfully eliminated when the growth was performed on the $\mathrm{Gd}_{2} \mathrm{SiO}_{5}$ seeds oriented along cleavage planes. As for the light yield of Ce-doped $\mathrm{Gd}_{2} \mathrm{SiO}_{5}$, it was several times less than that of Ce-doped $\mathrm{Lu}_{2} \mathrm{SiO}_{5}$ and $\mathrm{Y}_{2} \mathrm{SiO}_{5}$ [19]. Moreover, doping of the $\mathrm{Ce}: \mathrm{Gd}_{2} \mathrm{SiO}_{5}$ with $0.1 \%$ Ca further decreased the light yield for about three times.

The attempt to grow solid solution (or mixed) crystals corresponding to $\left(\mathrm{Gd}_{x} \mathrm{Lu}_{1-x}\right)_{2} \mathrm{SiO}_{5}$ composition was reported in [16] assuming that in some range of the Gd-content the crystals will form the structure similar to that of non-admixed $\mathrm{Lu}_{2} \mathrm{SiO}_{5}$. Ce-doped crystals of $x=0,0.2,0.5,0.9$ and 1.0 were grown from inductively heated $\mathrm{Ir}$ crucibles in $\mathrm{N}_{2}+1-2 \% \mathrm{O}_{2}$ atmosphere. The crystals containing up to $50 \mathrm{~mol} \%$ of $\mathrm{Gd}$ had $\mathrm{Lu}_{2} \mathrm{SiO}_{5}$ structure. However, that with $x=0.9$ was isomorphic to $\mathrm{Gd}_{2} \mathrm{SiO}_{5}(x=1)$. As it was expected, the lattice parameters of the both type crystals $\left(\mathrm{Lu}_{2} \mathrm{SiO}_{5}\right.$ and $\left.\mathrm{Gd}_{2} \mathrm{SiO}_{5}\right)$ changed according to average ionic radius of the rare-earth metals participating in formation of the crystals. In both type crystals, the segregation coefficient of the main rare-earth (such as $\mathrm{Lu}$ for $\mathrm{Lu}_{2} \mathrm{SiO}_{5}$ ) exceeds unity, but that of other rare-earths was less than 1 . The segregation coefficient of Ce increased almost linearly with crystal composition from $\mathrm{Lu}_{2} \mathrm{SiO}_{5}$ to $\mathrm{Gd}_{2} \mathrm{SiO}_{5}$, and it was almost independent on the type of the crystal structure that was formed [16].

More detailed study of the Ce-doped mixed LSO-GSO crystals regarding the growth process and relation between the structure and scintillation characteristics has been published recently [58]. The occurrence of two $\mathrm{Ce}^{3+}$ luminescent centers in LSO, YSO, and GSO has been established in the early 1990's [56] given to two Lu or Gd sites in the structure mentioned above. EPR study determined [74] that about $95 \%$ of $\mathrm{Ce}^{3+}$ centers is located at bigger 7-coordinated site in LSO. The onset of excited state ionization of $\mathrm{Ce}^{3+}$ centers around room temperature was found by classical photoconductivity studies [75] and further described in detail by purely optical methods [76].

Large effort has been devoted to the study of afterglow of LSO:Ce which was an obstacle for its practical applications [77] and is related to the dominant TSL peak at about $350 \mathrm{~K}$, always observed in Ce-doped LSO or LYSO [78] (Fig. 8). The most recent models point to the agglomeration of $\mathrm{Ce}^{3+}$ centers with electron traps based on the oxygen vacancies where tunneling driven radiative recombination exists $[79,80]$. The above mentioned $\mathrm{Ca}$ or $\mathrm{Mg}$ co-doping in Ce-doped LSO or LYSO enabled its optimization regarding the minimization of afterglow (see Fig. 9), where older generation LYSO:Ce sample from [78] and latest commercial samples of LYSO:Ce,Ca and YSO:Ce from Proteus, see also [57], are compared. The 


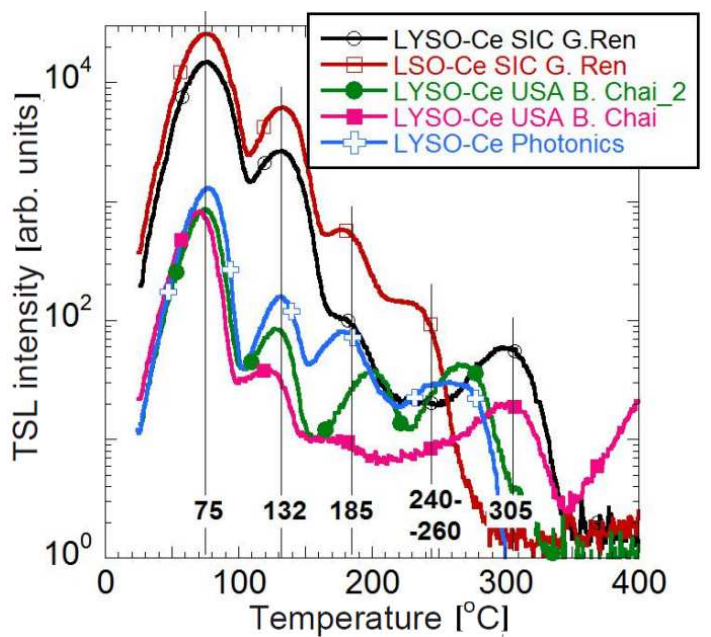

Fig. 8. TSL glow curves after X-irradiation at RT at LSO:Ce and LYSO:Ce. Reprinted from [78] with permission.

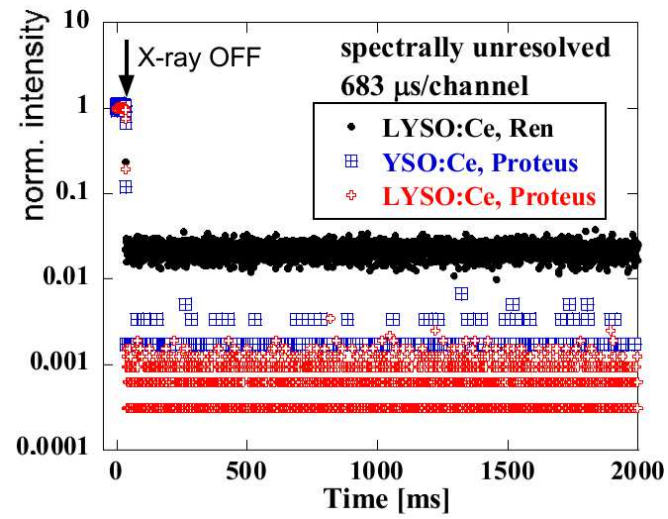

Fig. 9. Afterglow of LYSO:Ce (sample studied in [78]), LYSO:Ce, Ca and YSO:Ce (samples studied in [57]) after X-ray irradiation $(40 \mathrm{kV}, 10 \mathrm{~mA})$ switch-off at room temperature.

Ca co-doping of LSO:Ce resulted also in increase of LY and speed-up of scintillation decay [81, 82]. Optical, luminescence and scintillation characteristics of Ce-doped LSO, LYSO, YSO, GSO and LGSO are summarized in Table III.

\subsection{Bismuth germanate, $\mathrm{Bi}_{4} \mathrm{Ge}_{3} \mathrm{O}_{12}$ (BGO)}

Bismuth germanate, $\mathrm{Bi}_{4} \mathrm{Ge}_{3} \mathrm{O}_{12}$ (BGO) is another popular scintillating crystal that is produced by various melt growth techniques for a long time [20]. It is one of the most commercialized scintillating materials due to its congruent melting and relatively low melting point. As a result, it is produced in relatively simple conditions including ordinary open-air atmosphere. Therefore, the $\mathrm{Bi}_{4} \mathrm{Ge}_{3} \mathrm{O}_{12}$ crystals are fabricated by various melt growth methods including CZ [20-22], Bridgman [83], micro-pulling-down [42, 84], and other techniques.

In the melt of $\mathrm{Bi}_{4} \mathrm{Ge}_{3} \mathrm{O}_{12}$ composition heated just above the melting point, the $\mathrm{Bi}_{2} \mathrm{O}_{3}$ is more volatile
$[20,84]$. Therefore, some non-stoichiometry may be induced in the melt when the $\mathrm{CZ}$ growth of $\mathrm{BGO}$ is progressed. This can be compensated with application of some excess of $\mathrm{Bi}_{2} \mathrm{O}_{3}$ in the starting melt. Moreover, in Bi-containing melts the $\mathrm{Bi}_{2} \mathrm{O}_{3}$ may be reduced to metallic Bi [20]. In such circumstances, the metallic Bi particles interact with crucible material of platinum forming a low melting-point alloy. This reduces lifetime of the crucible considerably. Nevertheless, the platinum remains material of choice for such growths because any other candidate materials were not found. The effect of the corrosion can be somehow suppressed using $\mathrm{O}_{2}$-rich atmosphere or pure oxygen. However, in most cases the growth is performed in air. Both resistive and inductive heatings are applied.

The BGO crystals reported in [21] were grown for research purposes from the inductively heated $\mathrm{Pt}$ crucibles of $\varnothing 34 \times 36 \mathrm{~mm}^{2}$ or $\varnothing 52 \times 54 \mathrm{~mm}^{2}$ in dimensions. The crystals were 14.3 and $22.1 \mathrm{~mm}$ in diameter. In both these cases the predetermined ratio between the diameters of the crystal and the crucible was adjusted to be constant (0.42). The crystals were grown on (111)-oriented seed with pulling rate of $6 \mathrm{~mm} / \mathrm{h}$.

The BGO growth process analyzed in [22] was mostly developed for commercialization of the crystals. The method is based on the low thermal gradient $\left(0.1-1{ }^{\circ} \mathrm{C} / \mathrm{cm}\right)$ conception described above for the growth of the $\mathrm{CdWO}_{4}$ crystals [15] and illustrated in Fig. 5, right. Application of such growth system allowed authors of [22] to produce transparent high-quality crystals of $\mathrm{BGO}$ with dimensions achieving $\varnothing 150 \times 400 \mathrm{~mm}^{2}$. In the growth conditions applied (Fig. 5, right), the visual control of the meniscus and the growth interface was not possible, because the lid sited on the top of the crucible disturbed the view. Therefore, the seeding and the growth were controlled with precise weight sensing system. The platinum lid on the top reflected the thermal radiation making the radial and axial temperature gradients as low as $0.05-0.10^{\circ} \mathrm{C} / \mathrm{cm}$. This was positive factor with respect to protection of the melt from local overheating. Also, this lid played some role in suppressing evaporation of volatile constituents from the surface of the melt.

Because of low temperature gradients, it was possible to set crystal to crucible diameters ratio as high as 0.8 . Therefore, similarity of the growth system setup illustrated in Fig. 5 (right) and the Bridgman growth was noticed in [22]. However, compared to the Bridgman method, the low temperature gradient $\mathrm{CZ}$ system was able to perform growth of crystals with their rotation that provided better mixing of the melt.

Luminescence properties of the $\mathrm{Bi}_{4} \mathrm{Ge}_{3} \mathrm{O}_{12}$ were described for the first time in 1973 by Weber and Monchamp [85]. Broadband emission peaking around $480 \mathrm{~nm}$ (see inset in Fig. 10) with large Stokes shift of $14000 \mathrm{~cm}^{-1}$ was ascribed to ${ }^{3} P_{1}{ }^{1} S_{0}$ transition at $\mathrm{Bi}^{3+}$. The onset of thermal quenching was found around $250 \mathrm{~K}$, see Fig. 10, so that quantum efficiency of the luminescence center around room temperature is of about 0.13 


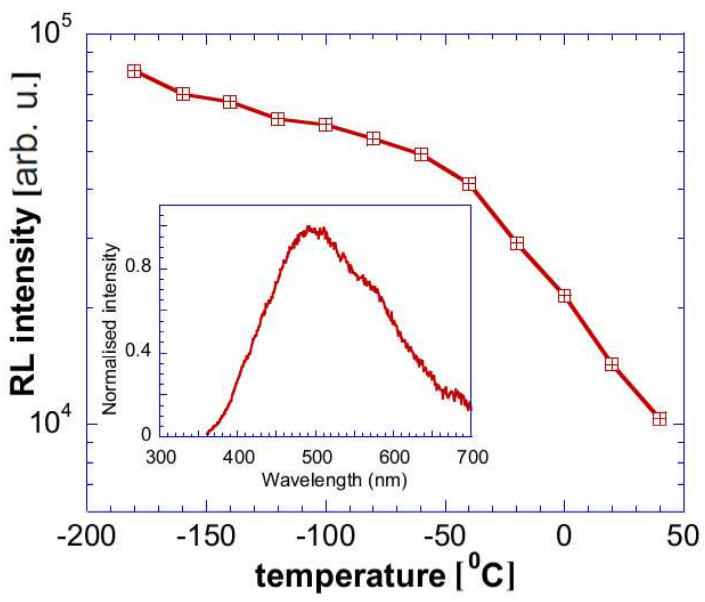

Fig. 10. Temperature dependence of radioluminescence intensity of BGO at room temperature excited by X-rays, $40 \mathrm{kV}$. Spectrum shape is in the inset.

and is strongly temperature dependent. Later detailed luminescence study ascribed this emission to self-trapped exciton around $\mathrm{Bi}\left(\mathrm{GeO}_{4}\right)_{6}$ structural unit [86]. Optical, luminescence and scintillation characteristics of BGO are summarized in Table III.

\subsection{Lutetium-aluminum perovskite, $\mathrm{LuAlO}_{3}$ ( $\mathrm{LuAP}$ )}

Behavior of $\mathrm{LuAlO}_{3}$ perovskite phase at high temperatures approaching its melting point is complicated and difficult to resolve $[4,87]$. Compared to its analog of $\mathrm{Ce}: \mathrm{YAlO}_{3}$, the $\mathrm{Ce}: \mathrm{LuAlO}_{3}$ scintillating crystals attract much attention as a result of its greater density and greater stopping power following from the substitution of relatively light $\mathrm{Y}$ with heavy Lu. On the other hand, increased content of yttrium in the $(\mathrm{Y}, \mathrm{Lu}) \mathrm{AlO}_{3}$ solid solution improves stability of the growth [4].

One of the successful growth of the Ce:LuAlO 3 perovskite crystals was reported in [23]. The crystals were grown from $\varnothing 50 \times 50 \mathrm{~mm}^{2}$ iridium crucible in the $\mathrm{N}_{2}$ atmosphere. The pulling and rotation rates were $1 \mathrm{~mm} / \mathrm{min}$ and $15 \mathrm{rpm}$, respectively. High quality macro-defect-free crystal of $\varnothing 20 \times 50 \mathrm{~mm}^{2}$ in dimensions was produced with a well-established shape resulting from application of diameter control system that considered lowering level of the melt in the crucible. The Lu-rich $\mathrm{LuAlO}_{3}$ crystals reported in [23] were activated with Ce and co-activated with $\mathrm{Ce}+\mathrm{Mo}$. Formation of $(\mathrm{Y}, \mathrm{Lu}) \mathrm{AlO}_{3}$ crystals was also discussed in some detail. The growth of $\mathrm{Ce}: \mathrm{LuAlO}_{3}$ from the melts containing $0.5-2.0 \%$ of Ce (with respect to Lu content as a host cation) in molybdenum crucibles was reported in [24], and the segregation coefficient of Ce for such process was reported to be about 0.4. As a result, the content of Ce in the crystal was approximately $0.2-0.8 \%$. Some of the crystals were "contaminated" with secondary garnet phase of $\mathrm{Lu}_{3} \mathrm{Al}_{5} \mathrm{O}_{12}$.

Luminescence of Ce-doped $\mathrm{YAlO}_{3}$ crystal was described by Weber [88], and favorable scintillation characteristics were reported somewhat later by several groups

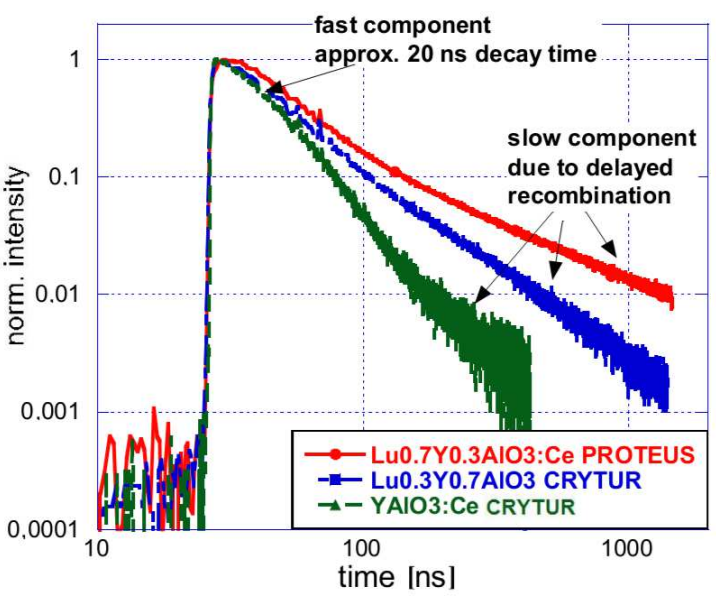

Fig. 11. Normalized scintillation decays of aluminum perovskites, composition in legend, excitation by $662 \mathrm{keV}$ ( ${ }^{137} \mathrm{Cs}$ radioisotope), the data are from [96].

[89-91]. Research activity in the field of aluminum perovskites was reviewed in $[52,69]$. Emission peak in near ultraviolet at $360-370 \mathrm{~nm}$, photoluminescence decay time of $18 \mathrm{~ns}$, and thermal stability of luminescence and scintillation parameters to $500 \mathrm{~K}$, together with excellent energy resolution around $4.5 \%$ at $662 \mathrm{kV}$ make this material very attractive for various applications. Nevertheless, complicated growth of LuAP or Lu-rich $(\mathrm{Lu}, \mathrm{Y}) \mathrm{AlO}_{3}$ makes its manufacturing cost very high and only few industrial scale producers appeared and for limited time only [92]. Moreover, with increasing Lu content light yield of the material drops down almost to $50 \%$ of YAP:Ce. Similarly to garnets, shallow electron trap exists in the materials that are well visible in thermo-luminescence, and the origin of some of them was determined by EPR measurements [93, 94]. In fact, increasing amount of $\mathrm{Lu}$ in $(\mathrm{Lu}, \mathrm{Y}) \mathrm{AlO}_{3}$ :Ce makes the depth of traps bigger [78, 95]; the amount of slow components in scintillation decay strongly increases (Fig. 11) which is probably the main cause of LY decrease [96]. Optical, luminescence and scintillation characteristics of Ce-doped YAP and LuAP are summarized in Table III.

\section{Important non-oxide crystals}

The growth aspects of two non-oxide crystals are overviewed below. One of the problems of the growth of such crystals is associated with starting materials because of their hygroscopic nature. Therefore their initial treatment and preparation for the growth procedure need considerable technically complicated precautions when compared with the oxide crystals discussed above.

\subsection{Ce-doped and Eu-doped $\mathrm{LiCaAlF}_{6}$}

Initially the Ce-doped lithium-calcium-aluminum fluorite ( $\mathrm{LiCAF}$ ) with colquirite-type structure was considered as excellent material for UV solid-state lasers [26]. However, lately it was proposed to be used as scintillating substance [25, 97, 98]. This crystal melts congruently. It is normally grown by $\mathrm{CZ}$ method from $\mathrm{Pt}$ or carbon 
crucibles under $\mathrm{CF}_{4}$ atmosphere to avoid contamination of the melt and the solid with oxygen. Both resistive [28] and inductive [27] heating methods are applied to produce the melts used for the growths.

The typical procedure for the growth of undoped $\mathrm{LiCaAlF}_{6}$ is described in [28]. The crystals were grown by $\mathrm{CZ}$ method in a vacuum tight chamber from the resistively heated $\mathrm{Pt}$ crucibles with crystal diameter control system. The powders of high-purity starting materials were mixed together and charged into the crucible. The pre-growth treatment of starting materials involved several steps described below, see also [28, 29]:

1. The growth chamber with starting materials in the crucible is evacuated $\left(10^{-3} \mathrm{~Pa}\right)$ to remove moisture and oxygen traces from the starting materials and the interior surfaces of the chamber. At the same time, the crucible is heated from room temperature to $700{ }^{\circ} \mathrm{C}$ for $12 \mathrm{~h}$.

2. The high-purity (99.99\%) [28] or (99.9999\%) [29] $\mathrm{CF}_{4}$ gas is slowly injected into the chamber.

3. Thereafter, heating of the starting materials is performed until their complete melting at approximately $820^{\circ} \mathrm{C}$.

The growth in [28] was performed using typical process similar to that illustrated in Fig. 1. The crystals were grown along $a$-axis following orientation of undoped $\mathrm{LiCaAlF}_{6}$ seed pulled with the rate of $0.8-1.0 \mathrm{~mm} / \mathrm{h}$. The seed rotation rate was $8-15 \mathrm{rpm}$.

The LiCAF crystals of $76 \mathrm{~mm}$ ( 3 inches) in diameter reported in [28] contained inclusions. This was associated with instability of the solid/liquid interface. Improvement of the interface behavior can be made through adjustment of the rotation rate to its optimal magnitude. Also, changing the melt level in the crucible could uncontrollably modify the temperature gradients established around the crystal and especially at the vicinity of the growth front. Partial stabilization of these thermal conditions can be made by displacing the crucible in vertical (upward) direction. After such maneuvers the number of the inclusions was reduced [28]. However, this positive result was accompanied with intense crack formation that was most probably result of high temperature gradient and increased thermal stresses acting in the crystal at the cooling stage. To avoid crack formation, the as grown crystal and the crucible with rest of the melt were displaced in downward direction after the crystal was separated from the melt and the growth was completed. This way, the cooling of both was performed in low temperature gradient environment. As a result, the as treated crystal was free of both the inclusions and cracks. It was noted in [28] that surface of the crystal shoulder was coated with some particles of $\mathrm{LiF}$ and $\mathrm{AlF}_{3}$, however, interior part of the crystal was transparent. Vaporization of $\mathrm{LiF}$ and $\mathrm{AlF}_{3}$ from the surface of the melt was also noticed in [26].

Growth of Ce-doped $\mathrm{LiCaAlF}_{6}$ is generally similar to that of described above. The Ce-doped LiCAF crystals of
25 and $50 \mathrm{~mm}$ in diameter and up to $100 \mathrm{~mm}$ in length were grown in [25] from $\mathrm{Pt}$ crucible also in $\mathrm{CF}_{4}$ atmosphere. The melt contained $0.5 \mathrm{~mol} . \%$ of $\mathrm{CeF}_{3}$ and $\mathrm{NaF}$ was used as a charge compensator.

The growth of Ce-doped LiCAF reported in [29] was performed from the melts enriched with $1 \mathrm{~mol} . \%$ of $\mathrm{LiF}$ and $\mathrm{AlF}_{3}$ to compensate their vaporization from the melt. Also 1 mol.\% of $\mathrm{CeF}_{3}$ and $\mathrm{NaF}$ were charged into the starting mixture to maintain presence of the Ce-dopant and its charge compensation. The crystals were grown from $\mathrm{Pt}$ crucible on $a$-axis oriented LiCAF seed with pulling rate of $1 \mathrm{~mm} / \mathrm{h}$ and the rotation rate of $10 \mathrm{rpm}$. The $\varnothing 18 \times 60 \mathrm{~mm}^{2}$ crystals produced in such conditions were visually defect-free, and they did not contain any cracks, bubbles, inclusions, and/or other substances as $\mathrm{LiF}$ and $\mathrm{AlF}_{3}$ on the surface. The segregation coefficient of $\mathrm{Ce}^{3+}$ was calculated based on the results of composition measurements, and its value was determined to be $K\left(\mathrm{Ce}^{3+}\right)=0.021$. In spite of low segregation coefficient, the distribution of the Ce-dopant along growth axis was reasonably uniform probably due to the low solidification fraction realized in these processes (about $25 \%$ only). Nevertheless, noticeable increase of the Ce content with solidification fraction was detected [29]. On the other hand, this did not affect uniformity of the lattice parameters.

In the $\mathrm{LiCaAlF}_{6}$ structure, the $\mathrm{Ca}^{2+}$ host cation is substituted by the $\mathrm{Ce}^{3+}$ dopant. This substitution was very low (considerably less than $1 \%$ ). That is why the crystals demonstrated perfect uniformity regarding the lattice parameters measured along the growth axis. The crystal of greater diameter $(25 \mathrm{~mm})$ had tendency to form inclusions, cracks, and impurity phase (at the bottom part of the crystal). It was noted that when the inclusions were formed in the shoulder part they were observed along the whole crystal length. To avoid this problem, more careful and "smooth" increase of the crystal diameter at the beginning of the growth was recommended [29]. The crystals produced at solidification fractions exceeding $70 \%$ contained inclusions of $\mathrm{CaF}_{2}$. This was result of enrichment of the melt with $\mathrm{CaF}_{2}$ following progressed evaporation of $\mathrm{LiF}$ and $\mathrm{AlF}_{3}$ from the melt surface. Therefore, the crystals of acceptable quality were produced at total solidification fractions not exceeding 60\%. Enrichment of the melt with $\mathrm{CeF}_{3}$ and $\mathrm{NaF}$ could be another source of changing the composition of the residual melt because of low segregation coefficient of Ce.

For the growth of the 2 mol.\% Eu-doped $\mathrm{LiCaAlF}_{6}$ crystals, the system equipped with inductive heating and automatic diameter control was applied [27]. $\mathrm{EuF}_{3}$ was used as a source of Eu-dopant. The crucible and the fragments of thermal insulation were produced from high-purity graphite. The crystal produced using $c$-axis oriented $\mathrm{LiCaAlF}_{6}$ crystal as a seed was about $50 \mathrm{~mm}$ in diameter and had no visible defects.

Radio-luminescence spectra in Fig. 12 show the peak positions at about $285 \mathrm{~nm}$ and $368 \mathrm{~nm}$ for the Ce- and Eu-doped LiCAF, respectively, and provide a quantita- 


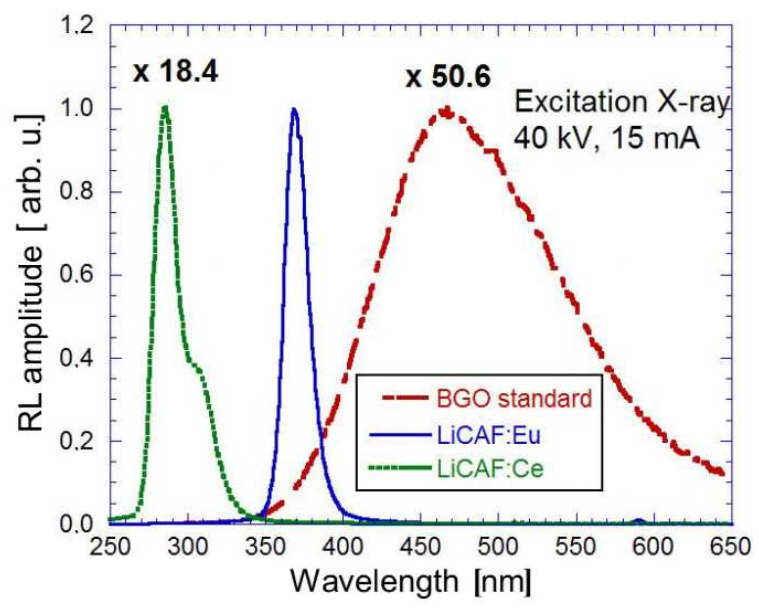

Fig. 12. Radio-luminescence spectra of the Ce- and Eu-doped LiCAF compared with the BGO standard scintillator, see also [62]. Spectra can be compared in an absolute scale.

tive comparison of scintillation efficiency of the Ce- and Eu-doped LiCAF and standard BGO scintillator under $\mathrm{X}$-ray excitation. After integration of the spectra (spectra considered in appropriate units as radiation flux vs. energy) the ratio of emission intensities is $0.8: 9: 1$, respectively. The difference of more than one order of magnitude between the Ce and Eu-doped LiCAF points to significant efficiency loss in the former.

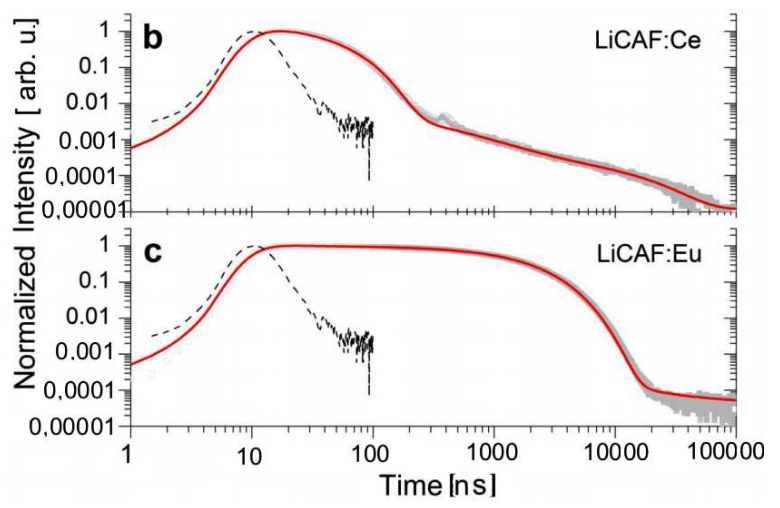

Fig. 13. Scintillation decay of (a) Ce-doped LiCAF, and (b) Eu-doped LiCAF under nanosecond soft X-ray excitation at RT. The fit by function $I(t)$ is given by solid line. The dashed line is the instrumental response, see [62] for further details.

Scintillation decays shown in Fig. 13 are approximated by the model function $I(t)$ :

$$
I(t)=a_{0}+a_{1} \mathrm{e}^{-t / \tau_{1}}+a_{2} \mathrm{e}^{-t / \tau_{2}}+(b t+c)^{-p}
$$

and has been chosen to include two excited state levels or one excited state and one shallow trap levels given by exponential terms, and an additional tunneling and/or other recombination process coming from the transfer stage of scintillation mechanism given by the inverse power term, see [62] for further details. Leading exponential decay components with decay times of $34.7 \mathrm{~ns}$ and $1.67 \mu$ s are due to $5 d-4 f$ transition of $\mathrm{Ce}^{3+}$ and $\mathrm{Eu}^{2+}$ emission centers, respectively. Optical, luminescence and scintillation characteristics of $\mathrm{Ce}$ and Eu-doped LiCAF are summarized in Table III.

\subsection{Ce-doped lanthanum bromide, Ce:LaBr 3}

Ce-doped lanthanum bromide $\left(\mathrm{LaBr}_{3}\right)$ is another non-oxide inorganic scintillator that is produced commercially in last years. It demonstrates very high light yield, excellent energy resolution, and fast decay [30]. $\mathrm{LaBr}_{3}$ crystals have hexagonal structure that is isomorphic with $\mathrm{UCl}_{3}$ [31]; it belongs to the space group of $P 63 / \mathrm{m}$. The density of this crystal is comparatively high $\left(5.3 \mathrm{~g} / \mathrm{cm}^{3}\right)$. It melts congruently at temperature of $783^{\circ} \mathrm{C}$ that is typically low for this type of materials. Therefore, according to $[30,34]$, these crystals can be grown using the Bridgman and Czochralski techniques from the melt. Actual Bridgman processes were performed for the growth of $\mathrm{LaBr}_{3}$ [30] using ultra-dry forms of $\mathrm{LaBr}_{3}$ and $\mathrm{CeBr}_{3}$ of $99.99 \%$ purity. The crystals were produced with $0.2 \%$, $0.5 \%, 1.3 \%$, and $5 \%$ of dopant content.

No considerable details available for the growth process itself, and most reports on characterization of $\mathrm{LaBr}_{3}$ are based on the examinations of the crystals produced by Saint Gobain Ceramics and Plastics Inc. [32, 33]. This company reported growth of the crystals of $127 \mathrm{~mm}$ (5 inches) in diameter back in 2006 [32] and growth procedure and/or parameters of the process are not disclosed.

During last 15 years the research on fast and efficient scintillators focused also on the new family of rare-earth (mostly La, Lu) halides where some of them showed extremely high light yield and excellent energy resolution. The Ce-doped $\mathrm{LaCl}_{3}, \mathrm{LaBr}_{3}$ and $\mathrm{LuI}_{3}$ appeared as the most promising compositions and their characteristics are listed in Table III where also scintillation time decay, LY and energy resolution are given for a specific Ce concentrations. Further information about their luminescence and scintillation characteristics can be found for $\mathrm{LaCl}_{3}$ :Ce in $[63,64], \mathrm{LaBr}_{3}: \mathrm{Ce}[63,65]$ and $\mathrm{LuI}_{3}: \mathrm{Ce}$ $[66,67]$.

\section{Search for new materials through combinatorial growth of micro-scale crystals}

Development of new scintillating crystals is always resource- and time-consuming. Therefore, preliminary testing of small crystals obtained with alternative melt growth techniques that are generally transferable to the Czochralski process is sometimes practiced. Particularly, the crystals of few $\mathrm{mm}$ in dimensions available from the micro-pulling-down ( $\mu$-PD) process are often (but not always) sufficient for the first round characterization of their physical properties. This was proven experimentally when studies of hundreds of new oxides, fluorides, and other non-fluoride halide crystals including chlorides, bromides, and iodides were performed especially in the past two decades. Many types of optical characterizations of the materials do not require massive ingots of 
the substance of interest, and few millimeter specimens produced after appropriate cutting and polishing are acceptable for preliminary inspection. In normal practice, when the as grown crystals have macro-dimensions, the millimeter-scale specimens required for the inspection are cut from the bulk material. When these dimensions are acceptable, the $\mu$-PD process becomes method of choice.

Regarding the structural quality, the perfection of the $\mu$-PD crystals in some cases is comparable to that of the crystals produced by conventional melt growth methods. For example, the quality of the $\mu$-PD rare-earth sesquioxide crystals was similar to those grown by the $\mathrm{CZ}$ method. According to the rocking curve measurements reported in [99], the full width at half maximum (FWHM) were 90 arcsec, 100 arcsec, and 217 arcsec for the Tm: $\mathrm{Y}_{2} \mathrm{O}_{3}, \mathrm{Tm}: \mathrm{Sc}_{2} \mathrm{O}_{3}$, and Tm: $\mathrm{Lu}_{2} \mathrm{O}_{3} \mu$-PD crystals. Some of the $\mu$-PD crystals may have macroscale dimensions with cross-section exceeding $5 \mathrm{~mm}$. Such materials can be certainly considered as macrocrystals ready for complete characterization.

\section{Summary}

The Czochralski method is one of the oldest and most developed crystal growth techniques regarding either an adequate understanding of the physical phenomena observed during solidification process or its practical expansion especially in the industrial scale production. It is widely used for the growth of large-size and high-quality single-crystalline cylindrical ingots of various chemical natures for a range of technical applications. Mass production of scintillating detectors is one of such applications that require application of well-established growth procedure because of large amount of crystalline material necessary. For example, traditional PET scanners require several thousands of high-quality single crystalline detectors that assembled into ring-shaped array [100] with dimensions comparable to that of human body and appropriate for millimeter-scale accuracy of image reconstruction. The Czochralski crystal growth technology is one of very few melt growth method that in a high degree satisfy optimal combination of crystal quality, crystal dimensions, and reasonable cost of produced crystals considering price of individual scintillating detector. The growth processes and material characteristics overviewed above illustrate applicability of the Czochralski method for the growth of single crystals having outstanding scintillating properties.

\section{Acknowledgments}

This work is partially supported by (i) Japan Society for the Promotion of Science (JSPS) Grant-in-Aid for Exploratory Research (AY), (ii) the funding program for next generation world-leading researchers, JSPS, (iii) Development of Systems and Technology for Advanced Measurement and Analysis, Japan Science and Technology Agency (JST), (iv) Adaptable \& Seamless Technology Transfer Program through Target-driven R\&D (A-STEP) and JST, (v) Supporting Industry program, Ministry of Economy, Trade and Industry (METI). In addition, we would like to thank following persons for their support: Mr. Yoshihiro Nakamura in Institute of Multidisciplinary Research for Advanced Materials (IMRAM), Tohoku University and Mr. Hiroshi Uemura, Ms. Keiko Toguchi and Ms. Megumi Sasaki, Ms. Yumiko Saijo in IMR. Some part of this work was carried out under the collaboration program of Cooperative Research and Development Center for Advanced Materials, IMR, Tohoku University. Authors thanks to Mr. Sugawara, Ms. Nomura in Cryst. Growth \& Design. Partial support of the Czech project supporting the Czech-Japan collaboration, MEYS, KONTAKT II, no. 12150 is gratefully acknowledged. Thanks are due to A. Beitlerova and V. Jary for radioluminescence and afterglow measurements and W. Chewpraditkul for providing the data for Fig. 11.

\section{References}

[1] D.J. Robbins, J. Electrochem. Soc. 127, 2694 (1980).

[2] A. Lempicki, A.J. Wojtowicz, E. Berman, Nucl. Instrum. Methods Phys. Res. A 333, 304 (1993).

[3] M.J. Weber, J. Lumin. 100, 35 (2002).

[4] M. Nikl, Meas. Sci. Technol. 17, R37 (2006).

[5] K. Kamada, K. Tsutsumi, Y. Usuki, H. Ogino, T. Yanagida, A. Yoshikawa, IEEE Trans. Nucl. Sci. 55, 1488 (2008).

[6] T. Yanagida, M. Sato, K. Kamada, Y. Fujimoto, Y. Yokota, A. Yoshikawa, V. Chani, Opt. Mater. 33, 413 (2011).

[7] A. Yoshikawa, Y. Fujimoto, A. Yamaji, S. Kurosawa, J. Pejchal, M. Sugiyama, S. Wakahara, Y. Futami, Y. Yokota, K. Kamada, K. Yubuta, T. Shishido, M. Nikl, Opt. Mater. (2013).

[8] H. Kimura, H. Maeda, M. Sato, J. Cryst. Growth 74, 187 (1986).

[9] K. Kamada, T. Yanagida, J. Pejchal, M. Nikl, T. Endo, K. Tsutsumi, Y. Fujimoto, A. Fukabori, A. Yoshikawa, IEEE Trans. Nucl. Sci. 59, 2112 (2012).

[10] K. Nitsch, M. Nikl, S. Ganschow, P. Reiche, R. Uecker, J. Cryst. Growth 165, 163 (1996).

[11] N. Senguttuvan, Premila Mohan, S. Moorthy Babu, C. Subramanian, J. Cryst. Growth 183, 391 (1998).

[12] A. Annenkov, E. Auffray, G. Drobychev, M. Korzhik, V. Kostylev, O. Kovalev, P. Lecoq, V. Ligoun, O. Missevitch, R. Zouevski, Nucl. Instrum. Methods Phys. Res. A 537, 173 (2005).

[13] T. Eissner, D.A. Bremer, V. Dormenev, P. Drexler, M. Moritz, R.W. Novotny, R. Schubert, Nucl. Sci. Symp. Med. Imag. Conf. N47-1, 2095 (2011).

[14] B.P. Nazarenko, V.N. Baumer, E.F. Dolzhenkova, M.B. Kosmyna, Inorg. Mater. 41, 1114 (2005)) (Translated from Neorganicheskie Materialy 41, 1261 (2005).

[15] E.N. Galashov, V.A. Gusev, V.N. Shlegel, Ya.V. Vasiliev, Crystallogr. Rep. 54, 689 (2009).

[16] G.B. Loutts, A.I. Zagumennyi, S.V. Lavrishchev, Yu.D. Zavartsev, P.A. Studenikin, J. Cryst. Growth 174, 331 (1997).

[17] Y.D. Zavartsev, S.A. Koutovoi, A.I. Zagumennyi, J. Cryst. Growth 275, e2167 (2005). 
[18] M.A. Spurrier, P. Szupryczynski, H. Rothfuss, K. Yang, A.A. Carey, C.L. Melcher, J. Cryst. Growth 310, 2110 (2008).

[19] M. Koschan, K. Yang, M. Zhuravleva, C.L. Melcher, J. Cryst. Growth 352, 133 (2012).

[20] G. Gevay, Prog. Cryst. Growth Charact. 15, 145 (1987).

[21] M. Berkowski, K. Iliev, V. Nikolov, P. Peshev, W. Piekarczyk, J. Cryst. Growth 108, 225 (1991).

[22] Ya.V. Vasiliev, R.R. Akhmetshin, Yu.A. Borovliev, D.N. Grigoriev, V.A. Gusev, V.N. Shlegel, V.P. Smakhtin, Nucl. Instrum. Methods Phys. Res. A 379, 533 (1996).

[23] W. Drozdowski, A.J. Wojtowicz, T. Łukasiewicz, J. Kisielewski, Nucl. Instrum. Methods Phys. Res. A 562, 254 (2006).

[24] W.W. Moses, S.E. Derenzo, A. Fyodorov, M. Korzhik, A. Gektin, B. Minkov, V. Aslanov, IEEE Trans. Nucl. Sci. NS-42, 275 (1995).

[25] A. Gektin, N. Shiran, S. Neicheva, V. Gavrilyuk, A. Bensalah, T. Fukuda, K. Shimamura, Nucl. Instrum. Methods Phys. Res. A 486, 274 (2002).

[26] K. Shimamura, S.L. Baldochi, I.M. Ranieri, H. Sato, T. Fujita, V.L. Mazzocchi, C.B.R. Parente, C.O. Paiva-Santos, C.V. Santilli, N. Sarukura, T. Fukuda, J. Cryst. Growth 223, 383 (2001).

[27] T. Yanagida, N. Kawaguchi, Y. Fujimoto, K. Fukuda, Y. Yokota, A. Yamazaki, K. Watanabe, J. Pejchal, A. Uritani, T. Iguchi, A. Yoshikawa, Opt. Mater. 33, 1243 (2011).

[28] H. Sato, A. Bensalah, A. Yoshikawa, M. Nikl, H. Machida, T. Fukuda, Opt. Mater. 24, 123 (2003).

[29] K. Shimamura, S.L. Baldochi, Na Mujilatu, K. Nakano, Z. Liu, N. Sarukura, T. Fukuda, J. Cryst. Growth 211, 302 (2000).

[30] K.S. Shah, J. Glodo, M. Klugerman, W.W. Moses, S.E. Derenzo, M.J. Weber, $L B N L-51793$, University of California, Oakland 2002.

[31] W.H. Zachariasen, J. Chem. Phys. 16, 254 (1948).

[32] P.R. Menge, Performance of Large BrilLanCe 380 (Lanthanum Bromide) Scintillators, SORMA XI, Ann Arbor (MI, USA), 2006.

[33] F. Quarati, A.J.J. Bos, S. Brandenburg, C. Dathy, P. Dorenbos, S. Kraft, R.W. Ostendorf, V. Ouspenski, A. Owens, Nucl. Instrum. Methods Phys. Res. A 574, 115 (2007).

[34] W.M. Higgins, A. Churilov, E. van Loef, J. Glodo, M. Squillante, K. Shah, J. Cryst. Growth 310, 2085 (2008).

[35] J. Czochralski, J. Phys. Chem. 91, 219 (1918).

[36] C.D. Brandle, J. Cryst. Growth 264, 593 (2004).

[37] M. Nikl, A. Yoshikawa, K. Kamada, K. Nejezchleb, C.R. Stanek, J.A. Mares, K. Blazek, Prog. Cryst. Growth Charact. Mater. 59, 47 (2013).

[38] M. Nikl, H. Ogino, A. Krasnikov, A. Beitlerova, A. Yoshikawa, T. Fukuda, Phys. Status Solidi A 202, R4 (2005).

[39] H. Ogino, A. Yoshikawa, M. Nikl, A. Krasnikov, K. Kamada, T. Fukuda, J. Cryst. Growth 287, 335 (2006).
[40] A. Yoshikawa, K. Kamada, F. Saito, H. Ogino, M. Itoh, T. Katagiri, D. Iri, M. Fujita, IEEE Trans. Nucl. Sci. 55, 1372 (2008).

[41] K. Kamada, T. Yanagida, T. Endo, K. Tsutumi, Y. Fujimoto, A. Fukabori, A. Yoshikawa, J. Pejchal, M. Nikl, Crystal Growth Des. 11, 4484 (2011).

[42] K. Kamada, T. Yanagida, J. Pejchal, M. Nikl, T. Endo, K. Tsutumi, Y. Usuki, Y. Fujimoto, A. Fukabori, A. Yoshikawa, J. Cryst. Growth 352, 84 (2012).

[43] Shaped Crystals: Growth by Micro-Pulling-Down Technique, Eds. T. Fukuda, V.I. Chani, Springer, Berlin 2007.

[44] R.D. Shannon, C.T. Prewitt, Acta Crystallogr. B 25, 925 (1969).

[45] G. Zhao, X. Zeng, J. Xu, Y. Xu, Y. Zhou, J. Cryst. Growth 253, 290 (2003).

[46] Ji. Kvapil, Jo. Kvapil, B. Manek, B. Perner, R. Autrata, P. Schauer, J. Cryst. Growth 52, 542 (1981).

[47] V. Bachmann, C. Ronda, A. Meijerink, Chem. Mater. 21, 2077 (2009).

[48] K. Kamada, T. Yanagida, T. Endo, K. Tsutumi, M. Yoshino, J. Kataoka, Y. Usuki, Y. Fujimoto, A. Fukabori, A. Yoshikawa, J. Cryst. Growth $\mathbf{3 5 2}$, 91 (2012).

[49] M. Nikl, A. Vedda, M. Fasoli, I. Fontana, V.V. Laguta, E. Mihokova, J. Pejchal, J. Rosa, Phys. Rev. B 76, 195121 (2007).

[50] M. Moszynski, M. Balcerzyk, M. Kapusta, A. Syntfeld, D. Wolski, G. Pausch, J. Stein, P. Schotanus, IEEE Trans. Nucl. Sci. 52, 3124 (2005).

[51] Y. Abraham, N.A.W. Holzwarth, R.T. Williams, Phys. Rev. B 62, 1733 (2000).

[52] M. Nikl, Phys. Status Solidi A 178, 595 (2000).

[53] A.A. Annenkov, M.V. Korzhik, P. Lecoq, Nucl. Instrum. Methods Phys. Res. A 490, 30 (2002).

[54] M. Itoh, H. Yokota, M. Horimoto, M. Fujita, Y. Usuki, Phys. Status Solidi B 231, 595 (2002).

[55] J.A. Mares, M. Nikl, E. Mihokova, A. Beitlerova, A. Vedda, C. D'Ambrosio, IEEE Trans. Nucl. Sci. 55, 1142 (2008).

[56] H. Suzuki, T.A. Tombrello, C.L. Melcher, J.S. Schweizer, Nucl. Instrum. Methods Phys. Res. A 320, 263 (1992).

[57] W. Chewpraditkul, C. Wanarak, T. Szczesniak, M. Moszynski, V. Jary, A. Beitlerova, M. Nikl, Opt. Mater. 35, 1679 (2013).

[58] O. Sidletskiy, A. Belsky, A. Gektin, S. Neicheva, D. Kurtsev, V. Kononets, C. Dujardin, K. Lebbou, O. Zelenskaya, V. Tarasov, K. Belikov, B. Grinyov, Cryst. Growth Des. 12, 4411 (2012).

[59] F. Antonangeli, N. Zema, M. Piacentini, Phys. Rev. B 37, 9036 (1988).

[60] E. Mihóková, M. Nikl, M. Bacci, M. Dušek, V. Petříček, Phys. Rev. B 79, 195130 (2009).

[61] V. Kolobanov, V. Mikhailin, N. Petrovnin, D. Spassky, Yu. Zorenko, Phys. Status Solidi B 243, R60 (2006).

[62] M. Nikl, P. Bruza, D. Panek, M. Vrbova, E. Mihokova, J.A. Mares, A. Beitlerova, N. Kawaguchi, K. Fukuda, A. Yoshikawa, Appl. Phys. Lett. 102, 161907 (2013). 
[63] K.W. Krämer, P. Dorenbos, H.U. Güdel, C.W.E. van Eijk, J. Mater. Chem. 16, 2773 (2006).

[64] O. Guillot-Noël, J.T.M. De Haas, P. Dorenbos, C.W.E. Van Eijk, K. Krämer, H.U. Güdel, J. Lumin. 85, 21 (1999).

[65] E.V.D. Van Loef, P. Dorenbos, C.W.E. van Eijk, K. Krämer, H.U. Güdel, Phys. Rev. B 68, 045108 (2003).

[66] J. Glodo, K.S. Shah, M. Klugerman, P. Wong, B. Higgins, P. Dorenbos, Nucl. Instrum. Methods Phys. Res. A 537, 279 (2005).

[67] M.D. Birowosuto, P. Dorenbos, C.W.E. van Eijk, IEEE Trans. Nucl. Sci. 52, 1114 (2005).

[68] S.Ph. Burachas, F.A. Danevich, A.Sh. Georgadze, H.V. Klapdor-Kleingrothaus, V. Kobychev, B.N. Kropivyansky, V.N. Kuts, A. Muller, V.N. Muzalevsky, A.S. Nikolaiko, O.A. Ponkratenko, V.D. Ryzhikov, A.S. Sai, I.M. Solsky, V.I. Tretyak, Yu.G. Zdesenko, Nucl. Instrum. Methods Phys. Res. A 369, 164 (1996).

[69] M. Nikl, V.V. Laguta, A. Vedda, Phys. Status. Solidi B 245, 1701 (2008).

[70] V.V. Laguta, M. Buryi, M. Nikl, J. Rosa, S. Zazubovich, Phys. Rev. B 83, 094123 (2011).

[71] A. Krasnikov, M. Nikl, S. Zazubovich, Phys. Status Solidi B 243, 1727 (2006).

[72] M.M. Chirila, K.T. Stevens, H.J. Murphy, N.C. Giles, J. Phys. Chem. Solids 61, 675 (2000).

[73] L. Nagornaya, G. Onyshchenko, E. Pirogov, N. Starzhinskiy, I. Tupitsyna, V. Ryzhikov, Yu. Galich, Yu. Vostretsov, S. Galkin, E. Voronkin, Nucl. Instrum. Methods Phys. Res. A 537, 163 (2005).

[74] L. Pidol, O. Guillot-Noel, A. Kahn-Harari, B. Viana, D. Pelenc, D. Gourier, J. Phys. Chem. Solids 67, 643 (2006).

[75] E. van der Kolk, S.A. Basun, G.F. Imbusch, W.M. Yen, Appl. Phys. Lett. 83, 1740 (2003).

[76] H. Feng, V. Jary, E. Mihokova, D. Ding, M. Nikl, G. Ren, H. Li, S. Pan, A. Beitlerova, R. Kucerkova, J. Appl. Phys. 108, 033519 (2010).

[77] P. Dorenbos, C.W.W. van Eijk, A.J.J. Bos, C.L. Melcher, J. Phys. Condens. Matter 6, 4167 (1994).

[78] M. Nikl, E. Mihokova, J. Pejchal, A. Vedda, M. Fasoli, I. Fontana, V.V. Laguta, V. Babin, K. Nejezchleb, A. Yoshikawa, H. Ogino, G. Ren, IEEE Trans. Nucl. Sci. 55, 1035 (2008).

[79] A. Vedda, M. Nikl, M. Fasoli, E. Mihokova, J. Pejchal, M. Dusek, G. Ren, C.R. Stanek, K.J. McClellan, D.D. Byler, Phys. Rev. B 78, 195123 (2008).

[80] S. Blahuta, A. Bessière, B. Viana, V. Ouspenski, E. Mattmann, J. Lejay, D. Gourier, Materials 4, 1224 (2011).
[81] M.A. Spurrier, P. Szupryczynski, K. Yang, A.A. Carey, C.L. Melcher, IEEE Trans. Nucl. Sci. 55, 1178 (2008).

[82] B. Viana, T.H. Maldiney, S. Blahuta, A. Béssi?re, D. Gourier, C. Richard, D. Scherman, V. Ouspenski, Proc. SPIE 8626, 86260R (2013).

[83] M. Kobayashi, K. Harada, Y. Hirose, M. Ishii, I. Yamaga, Nucl. Instrum. Methods Phys. Res. A 400 , 392 (1997).

[84] V. Chani, K. Lebbou, B. Hautefeuille, O. Tillement, J.-M. Fourmigue, Cryst. Res. Technol 41, 972 (2006).

[85] M.J. Weber, R.R. Monchamp, J. Appl. Phys. 44, 5495 (1973).

[86] R. Moncorge, B. Jacquier, G. Boulon, J. Lumin. 14 337 (1976).

[87] D. Klimm, J. Cryst. Growth 312, 730 (2010).

[88] M.J. Weber, J. Appl. Phys. 44, 3205 (1973).

[89] T. Takeda, T. Miyata, F. Muramatsu, T. Tomiki, J. Electrochem. Soc. 127, 438 (1980).

[90] E. Autrata, P. Schauer, J. Kvapil, Jos. Kvapil, Scanning 5, 91 (1983).

[91] V.G. Baryshevsky, M.V. Korzhik, V.I. Moroz, V.B. Pavlenko, A.A. Fyodorov, S.A. Smirnova, O.A. Egorycheva, V.A. Kachanov, Nucl. Instrum. Methods Phys. Res. 58, 291 (1991).

[92] J. Trummer, E. Auffray, P. Lecoq, A. Petrosyan, P. Sempere-Roldan, Nucl. Instrum. Methods Phys. Res. A 551, 339 (2005)

[93] A. Vedda, M. Fasoli, M. Nikl, V.V. Laguta, E. Mihokova, J. Pejchal, A. Yoshikawa, M. Zhuravleva, Phys. Rev. B 80, 045113 (2009).

[94] V.V. Laguta, M. Nikl, A. Vedda, E. Mihokova, J. Rosa, K. Blazek, Phys. Rev. B 80, 045114 (2009).

[95] A.N. Belsky, E. Auffray, P. Lecoq, C. Dujardin, N. Garnier, H. Canibano, C. Pedrini, A.G. Petrosyan, IEEE Trans. Nucl. Sci. 48, 1095 (2001).

[96] W. Chewpraditkul, A. Phunpueok, T. Szczesniak, M. Moszynski, V. Babin, M. Nikl, Phys. Status Solidi $A$ (2013).

[97] M. Nikl, N. Solovieva, E. Mihokova, M. Dusek, A. Vedda, M. Martini, K. Shimamura, T. Fukuda, Phys. Status Solidi A 187, R1 (2001).

[98] A. Yoshikawa, T. Yanagida, Y. Yokota, N. Kawaguchi, S. Ishizu, K. Fukuda, T. Suyama, K.J. Kim, J. Pejchal, M. Nikl, K. Watanabe, M. Miyake, M. Baba, K. Kamada, IEEE Trans Nucl. Sci. 56, 3796 (2009).

[99] A. Fukabori, V. Chani, K. Kamada, F. Moretti, A. Yoshikawa, Cryst. Growth Des. 11, 2404 (2011).

[100] J.A.K. Blokland, P. Trindev, M.P.M. Stokkel, E.K.J. Pauwels, Europ. J. Radiol. 44, 70 (2002). 